\title{
The low-resolution CCSM2 revisited: new adjustments and a present-day control run
}

\author{
M. Prange \\ MARUM - Center for Marine Environmental Sciences and Department of Geosciences, University of Bremen, Klagenfurter \\ Str., 28334 Bremen, Germany
}

Received: 26 July 2006 - Published in Ocean Sci. Discuss.: 18 August 2006

Revised: 17 April 2008 - Accepted: 18 April 2008 - Published: 26 May 2008

\begin{abstract}
The low-resolution (T31) version of the Community Climate System Model CCSM2.0.1 is revisited and adjusted by deepening the Greenland-Scotland ridge, changing oceanic mixing parameters, and applying a regional freshwater flux adjustment at high northern latitudes. The main purpose of these adjustments is to maintain a robust Atlantic meridional overturning circulation which collapses in the original model release. The paper describes the present-day control run of the adjusted model (referred to as "CCSM2/T31x3a") which is brought into climatic equilibrium by applying a deep-ocean acceleration technique. The accelerated integration is extended by a 100 -year synchronous phase. The simulated meridional overturning circulation has a maximum of $14 \times 10^{6} \mathrm{~m}^{3} \mathrm{~s}^{-1}$ in the North Atlantic. The CCSM2/T31x3a control run is evaluated against observations and simulations with other climate models. Most shortcomings found in the CCSM2/T31x3a control run are identified as "typical problems" in global climate modelling. Finally, examples (simulation of North Atlantic hydrography, West African monsoon) are shown in which CCSM2/T31x3a has a better simulation skill than the latest low-resolution Community Climate System Model release, CCSM3/T31.
\end{abstract}

\section{Introduction}

Transporting cold deepwater from the North Atlantic to the Southern Ocean and warm water masses in the upper layers in opposite direction, the present-day Atlantic meridional overturning circulation (AMOC) is associated with a substantial northward heat transport of order $10^{15} \mathrm{~W}$ (e.g. Ganachaud and Wunsch, 2000). During the past two decades

Correspondence to: M. Prange

(mprange@palmod.uni-bremen.de) of paleoceanographic and paleoclimatic research the role of the AMOC in driving or amplifying global climatic changes came more and more into focus. Strong variations in the AMOC might have induced changes in the global temperature distribution, wind fields and the hydrologic cycle. The possibility that the AMOC could change in the future (Meehl et al., 2007) motivates paleoceanographers to understand how it may have differed in the past.

For instance, it has been proposed that a strengthening of the AMOC during the early Pliocene led to an intensification of the hydrologic cycle at high northern latitudes (i.e. more snowfall) and, hence, was a necessary precondition for the onset of Northern Hemisphere glaciation around 3 million years ago (Haug and Tiedemann, 1998; Driscoll and Haug, 1998). It has also been suggested that AMOC changes played an important role in amplifying glacial-interglacial and interglacial-glacial transitions during the Quaternary (e.g. Piotrowski et al., 2005). Probably the most established example for AMOC-induced global climatic changes are the millennial-scale Dansgaard-Oeschger and Heinrich events of the last glacial. Dansgaard-Oeschger events (transitions between cold stadials and warm interstadials) took place within some decades and were accompanied by warmings of about $10^{\circ} \mathrm{C}$ over the Greenland ice sheet (Severinghaus and Brook, 1999). The significance of these warming events is corroborated by climate variations on a global scale, which can be correlated to the Dansgaard-Oeschger cycles (Voelker et al., 2002). Benthic isotope records from South Atlantic deep-sea cores suggest that these events were triggered by changes in the AMOC (Piotrowski et al., 2005). Heinrich events were associated with the coldest periods in the North Atlantic realm, but - like Dansgaard-Oeschger events - also had a global impact on the glacial climate featuring a hemispheric seesaw pattern (e.g. Prange et al., 2004, and references therein). Heinrich events were characterized by extremely high inputs of ice-rafted debris to the North Atlantic (Broecker et al., 1992), and it is generally accepted that

Published by Copernicus Publications on behalf of the European Geosciences Union. 


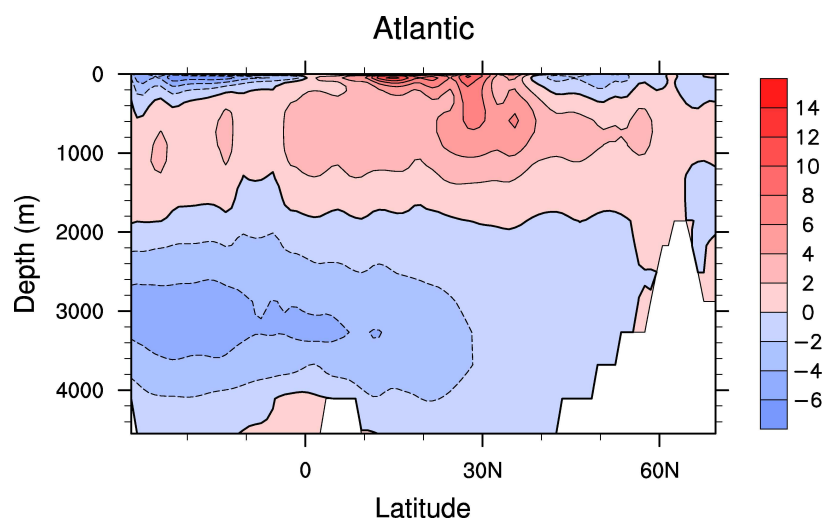

Fig. 1. Atlantic meridional overturning circulation (Sv) obtained with the Eulerian-mean velocity from the standard CCSM2/T31 control run with default settings and parameters. A 10-yr average is shown calculated from years 278-287 (the control run has started from observational data).

their climatic effect relied on the perturbation of North Atlantic Deep Water (NADW) formation by melting icebergs (e.g. Rahmstorf, 2002, and references therein). Freshwater perturbations in the North Atlantic were also likely to be responsible for the last two pronounced cold intervals, the Younger Dryas (ca. 13000 years ago) and the " $8 \mathrm{k}$ event" about 8200 years ago (Alley and Agustsdottir, 2005, and references therein). Less pronounced Holocene climatic shifts in the North Atlantic realm have recently been associated with moderate AMOC variations (Oppo et al., 2003; Schulz et al., 2007; Jongma et al., 2007). These few examples demonstrate that the AMOC is crucial for the understanding of past - and probably future - climate change. A climate model without representation of the AMOC is virtually useless for most paleo-relevant scientific questions.

Paleoclimatic model experiments usually require long integration times either to reach climatic equilibria which differ from the present-day situation or to simulate long-term (e.g. millennial) climatic trends and changes. To reduce computation time, numerical models used in paleoceanographic and paleoclimatic research are therefore often reduced in complexity (cf. Claussen et al., 2002) and/or employ relatively coarse grid resolutions. Low-resolution configurations of the fully-coupled NCAR (National Center for Atmospheric Research) Community Climate System Model CCSM have been released both for version 2.0.1 ("CCSM2/T31") and for version 3.0 ("CCSM3/T31"). In these so-called "paleo versions", the horizontal resolution of the atmospheric component is given by $\mathrm{T} 31$ spectral truncation $\left(3.75^{\circ}\right.$ by $3.75^{\circ}$ transform grid), whereas the ocean has a nominal resolution of $3.6^{\circ}$ by $1.6^{\circ}$ with 25 levels. While the present-day control run of CCSM3/T31 exhibits a robust thermohaline circulation in the Atlantic Ocean (Yeager et al., 2006), the AMOC spins down in CCSM2/T31 such that the net vol- ume export of NADW to the Southern Ocean drops below $2 \mathrm{~Sv}\left(1 \mathrm{~Sv}=10^{6} \mathrm{~m}^{3} \mathrm{~s}^{-1}\right.$; Fig. 1). Associated with the weak overturning circulation is a strong cold bias in the North Atlantic realm (not shown) and the formation of a distinct halocline in the northwestern Atlantic where sea surface salinities are several psu below observational values (Fig. 2). This renders CCSM2/T31 unsuitable for paleoclimate studies in which changes of the AMOC play a crucial role.

It is basically unclear why CCSM3/T31 simulates a robust AMOC, and why CCSM2/T31 does not. The application of a different model grid in the ocean component might play a role (cf. Yeager et al., 2006), but any change in the other model components of CCSM (atmosphere, land or sea ice) could contribute to the improvement of the AMOC simulation as well (albeit more indirectly). Either way, there seems to be no obvious reason why CCSM2/T31 should not be consigned to history in view of the release of CCSM3/T31. In the present paper, however, it is shown that the performance of CCSM2/T31 can substantially be improved by applying some modifications to the original model. The lowresolution version of CCSM2.0.1 with these adjustments included is referred to as CCSM2/T31 x3a to reflect the atmospheric resolution ("T31"), the average resolution of the ocean grid ("x3") as well as the implementation of adjustments ("a"). We shall see that CCSM2/T31x3a simulates a robust AMOC that is similar to the ocean circulation in CCSM3/T31. Even more interesting, there are several applications where CCSM2/T31x3a performs better than CCSM3/T31, depending on the phenomenon under investigation and its geographical location.

The present paper is devoted to the description of the present-day control run of CCSM2/T31x3a. Even though a detailed model intercomparison is far beyond the scope of this paper, examples shall be shown in which CCSM2/T31x3a provides a better simulation than CCSM3/T31. The following section describes the tuning of CCSM2/T31x3a. Section 3 describes and discusses the asynchronous integration technique which is used to achieve a statistical equilibrium climate state. The present-day climate from the CCSM2/T31x3a control run is presented in Sect. 4. The focus is placed on oceanic and atmospheric climatological means. The simulation skill for interannual variability in the tropical Pacific and North Atlantic regions is briefly discussed. CCSM2/T31x3a's control run is compared with other models - particularly with CCSM3/T31 - in Sect. 5. Conclusions are drawn in Sect. 6.

\section{CCSM2/T31x3a: components and adjustments}

The NCAR Community Climate System Model CCSM2.0.1 is composed of four separate model components: atmosphere, ocean, land and sea ice (Kiehl and Gent, 2004). In a parallel computing environment, these components run simultaneously and communicate information back and forth 


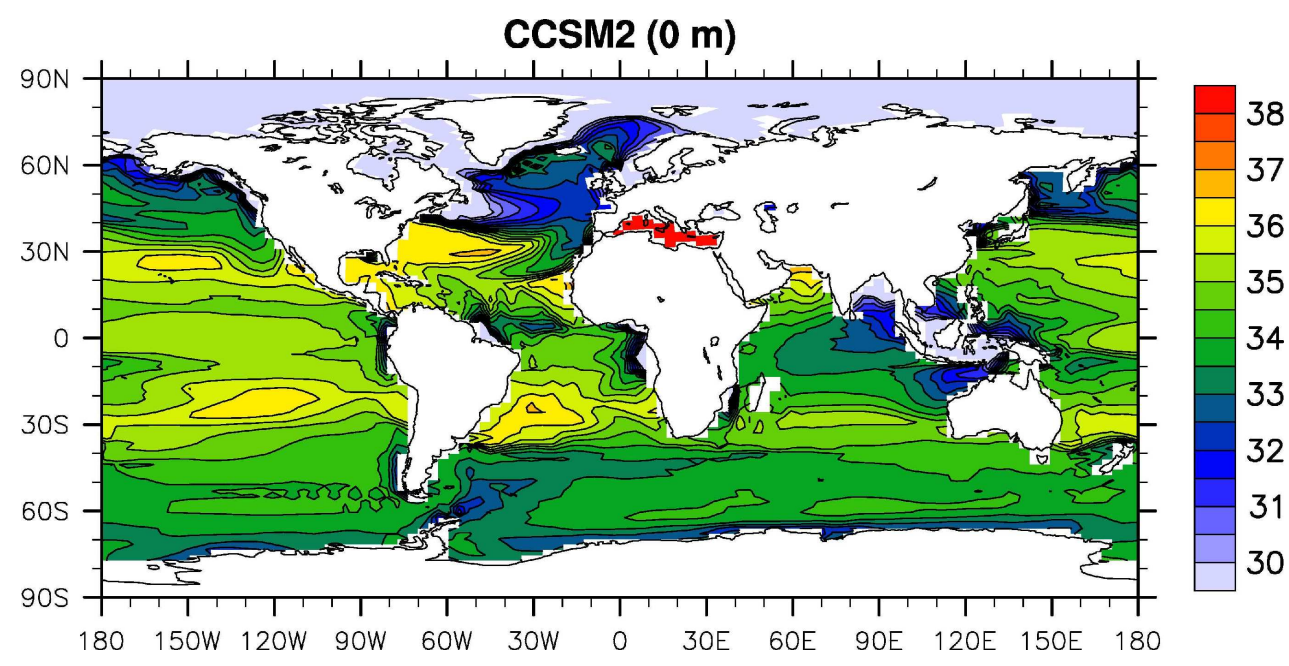

Fig. 2. Annual-mean sea surface salinity (psu) in the standard CCSM2/T31 control run with default settings and parameters. A 10-yr average is shown calculated from years $278-287$ of the simulation. The model output can be compared with observations shown in Fig. 14 .

via a central coupler. The atmosphere component is the Community Atmosphere Model CAM2, a global general circulation model developed from NCAR's CCM3 (Collins et al., 2003). CAM2 employs a spectral dynamical core (i.e. the numerical solutions of the partial differential equations are approximated using harmonics and involve the use of the Fast Fourier Transform; e.g. Canuto et al., 1988) and hybrid vertical coordinates with 26 levels, combining terrainfollowing sigma coordinates (which are defined by the ratio of the pressure at a given point in the atmosphere to the pressure on the surface of the earth underneath it) at the bottom with pressure-level coordinates at the top of the model. The ocean is represented by the z-coordinate, Bryan-Cox type (cf. Kantha and Clayson, 2000) Parallel Ocean Program POP 1.4 (Smith and Gent, 2002). The model employs an implicit free surface (Dukowicz and Smith, 1994), an anisotropic viscosity parameterization (Smith and McWilliams, 2003) and Gent and McWilliams' (1990) isopycnal mixing for tracers using the skew-flux form (Griffies, 1998). A non-local KPP (K-profile parameterization) scheme is applied for vertical mixing (Large et al., 1994). The sea-ice component is the Community Sea-Ice Model CSIM4 (Briegleb et al., 2002) with elastic-viscous-plastic dynamics scheme (Hunke and Dukowicz, 1997), an explicit brine-pocket parameterization (Bitz and Lipscomb, 1999) and an ice thickness distribution module that accounts for five ice thickness categories (Bitz et al., 2001). The land component of CCSM2.0.1 is the Community Land Model CLM2 (Vertenstein et al., 2002). It includes complex biogeophysics and hydrology along with a state-of-the-art river runoff module (Branstetter and Erickson, 2003). Detailed documentations of all model components and parameters can be found at www.ccsm.ucar.edu/ models/ccsm2.0.1.
In the framework of CCSM, atmosphere and land models share an identical horizontal grid. Likewise, ocean and sea ice use one and the same horizontal grid. In CCSM2/T31x3a, the ocean/sea-ice component is formulated on an orthogonal grid which shifts the north pole singularity into Greenland to avoid time-step constraints due to grid convergence. This grid is referred to as "gx3v4" (Fig. 3). It has a longitudinal resolution of $3.6^{\circ}$. The latitudinal resolution of " $\mathrm{gx} 3 \mathrm{v} 4$ " is variable, with finer resolution (approximately $0.9^{\circ}$ ) near the equator.

In CCSM2/T31x3a, several adjustments to the standard CCSM2.0.1 release are applied. The overall goal is to amplify the meridional overturning circulation in the Atlantic Ocean. Due to the computational expense of performing fully-coupled experiments systematic sensitivity studies, elucidating the effects of each modification separately, are not feasible for the time being. The tuning of CCSM2.0.1 is based on experience with other models. CCSM2/T31x3a includes the following adjustments:

- The Greenland-Scotland ridge is slightly deepened such that the sill depths are $\sim 590 \mathrm{~m}$ and $\sim 900 \mathrm{~m}$ in the Denmark Strait and in the Iceland-Scotland passage, respectively (Fig. 4). Given the rather coarse resolution of the "gx3v4" ocean grid, the new bathymetry is still appropriate. A deeper Greenland-Scotland ridge facilitates the exchange of dense water masses between the North Atlantic and the Nordic Seas where deep winter convection takes place (cf. Koesters et al., 2004).

- Background vertical mixing in the ocean is set to a constant value of $0.3 \mathrm{~cm}^{2} / \mathrm{s}$. In the default model set-up vertical background mixing increases from $0.1 \mathrm{~cm}^{2} / \mathrm{s}$ at the surface to $1.0 \mathrm{~cm}^{2} / \mathrm{s}$ at $5000 \mathrm{~m}$ depth (a value of 


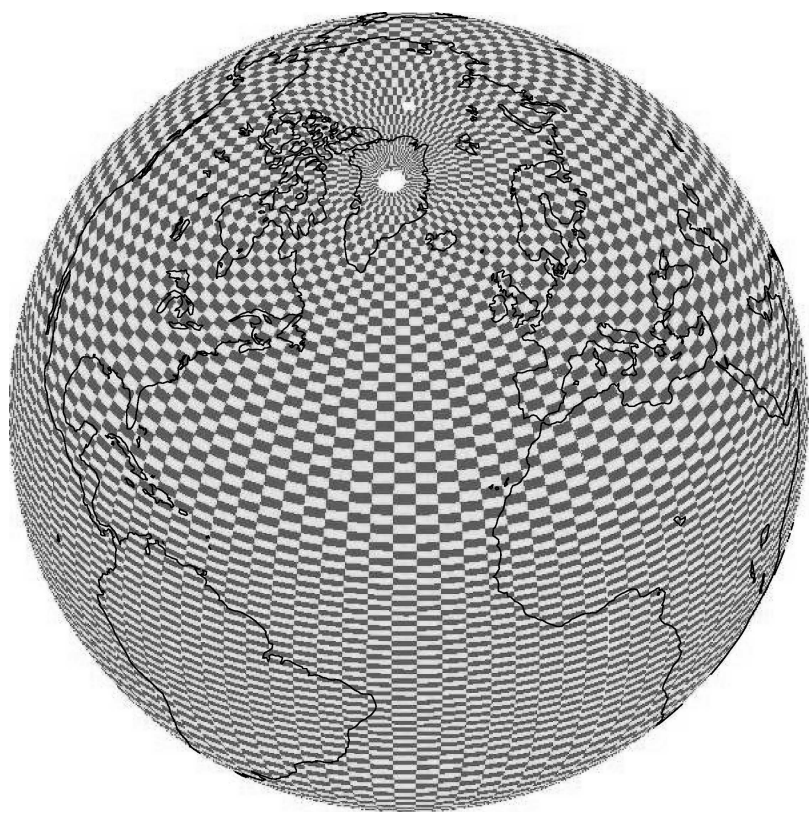

Fig. 3. Horizontal cell distribution of the ocean/sea-ice grid "gx3v4". Note the displaced north pole and the enhanced resolution at low latitudes.

$0.3 \mathrm{~cm}^{2} / \mathrm{s}$ is reached at about $2300 \mathrm{~m}$ depth). Thus, compared to the default setting, vertical mixing is slightly increased in the upper ocean below the surface boundary layer (alternatively, one could have applied geographically varying upper-ocean parameters with lower vertical diffusivity in the tropics and much higher values in the Southern Ocean where internal wave activity is known to be enhanced, see Gnanadesikan et al., 2006). Vertical mixing provides a mechanism for the conversion of cold deep waters into warm water of the upper layers. The crucial role of vertical mixing in driving the thermohaline circulation has been demonstrated in numerous studies (e.g. Bryan, 1987; Wright and Stocker, 1992; Marotzke, 1997; Prange et al., 2003).

- For the Redi and bolus parts of the Gent-McWilliams parameterization diffusivities are set to $1.2 \times 10^{7} \mathrm{~cm}^{2} / \mathrm{s}$. This represents a $50 \%$ increase compared to the default. It is expected that higher horizontal mixing counteracts halocline formation in the northern North Atlantic, thereby favouring convective activity and NADW formation (cf. Schmittner and Weaver, 2001).

- The coefficient used in the quadratic ocean bottom drag formula is increased from $10^{-3}$ to $10^{-2}$. The most important effect of this change is a substantial retardation of the flow through the shallow Bering Strait. This throughflow is associated with an import of relatively fresh water from the North Pacific to the Arctic Ocean and the Nordic Seas, where it is likely to affect convective activity. It has been shown in several model studies that a reduction of the Bering Strait throughflow strengthens the AMOC (e.g. Hasumi, 2002; Wadley and Bigg, 2002; Prange, 2003).

- At each ocean model time step, freshwater fluxes (precipitation plus river runoff) into the surface grid cells of the Arctic Mediterranean, Labrador Sea/Baffin Bay and Hudson Bay are reduced by $50 \%$. The corresponding amount of freshwater is homogeneously distributed over the entire Pacific Ocean (Fig. 5). This leads to an effective sea surface salinity increase in regions that are potentially important for NADW formation. Beyond these regions, the hydrological cycle is simulated without unphysical adjustments. This is a main advantage over the more common application of global fluxcorrection fields. The freshwater flux redistribution requires modifications in the POP Fortran code and it is presumably the most substantial change to the standard model set-up. Note that neither heat nor momentum flux corrections are implemented in CCSM2/T31x3a.

In addition to the model tuning which aims at boosting the AMOC, optimized sea-ice/snow albedos are applied based on results from stand-alone sea-ice model experiments: Maximum albedos for thick, dry sea ice are set to 0.82 and 0.38 for the visible and near-infrared spectral band, respectively. The near-infrared albedo for dry snow is set to 0.74 . No distinction is made between the hemispheres.

\section{Accelerated integration}

Accelerated integration techniques are often applied to climate models to reduce the computational expense. In order to obtain a present-day climatic equilibrium, a deepocean acceleration technique - which is highly efficient in the framework of CCSM2/T31 33 a - is employed here. This approach allows for increasing tracer time steps with depth, exploiting the relaxation of the Courant-Friedrichs-Lewy constraint due to diminishing current speeds in the deep ocean (Bryan and Lewis, 1979; Bryan, 1988). Such an asynchronous integration technique has proven useful for searching equilibrium solutions without any interest in the transient behaviour of the model: Once an equilibrium is reached (i.e. vanishing time-derivates in the model equations), the solution is independent of the time-stepping.

However, numerical acceleration techniques can severely distort the model physics. Two major concerns have been raised regarding asynchronous deep-ocean time-stepping. Firstly, this approach does not ensure tracer conservation. Conservation of heat and salt is violated whenever vertical fluxes occur between neighbouring grid boxes that solve the prognostic tracer equations with different time steps (Danabasoglu et al., 1996). Secondly, time-derivates never vanish 

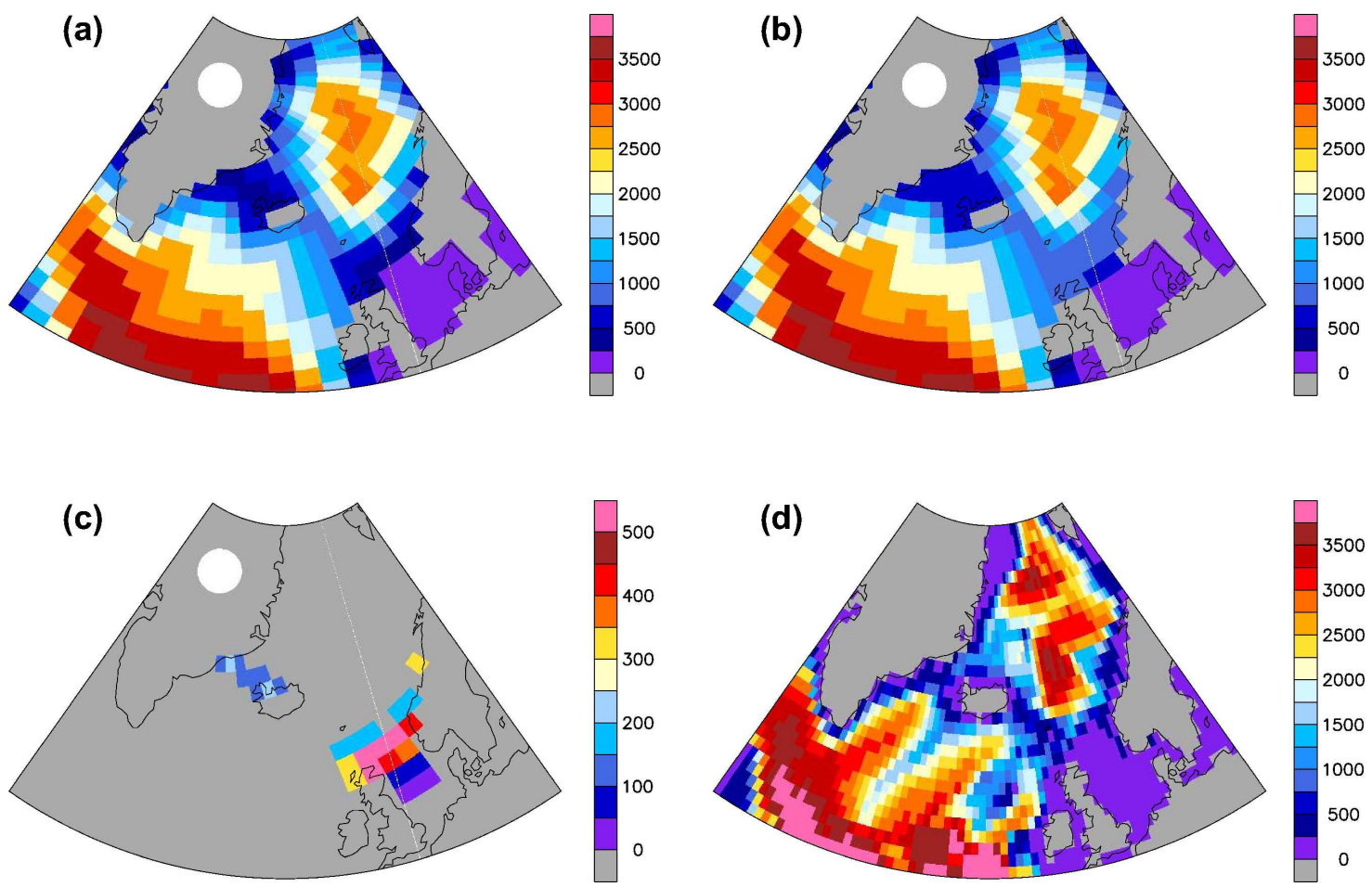

Fig. 4. Bathymetry around the Greenland-Scotland ridge: (a) Ocean depths (m) at tracer grid points in the original low-resolution CCSM2.0.1 release plotted in raster-mode to display the "gx3v4" ocean-grid structure; (b) same as (a) but for the new bathymetry used in CCSM2/T31x3a; (c) difference between CCSM2/T31x3a and original bathymetry; (d) real bathymetry (ETOPO60) for comparison.

in a realistically forced ocean model due to intra- and interannual variability. In order to quantify these errors, Danabasoglu (2004) recently applied accelerated integration methods to POP 1.4 subject to realistic forcing. Comparing equilibrium temperatures and salinities obtained by deep-ocean acceleration with those from a 10000 -year synchronous control run, he found that errors are of order $0.1 \mathrm{~K}$ and $0.1 \mathrm{psu}$, respectively, provided that two conditions are met: (i) vertical variations in time step are restricted to depths where vertical tracer fluxes (i.e. vertical gradients) are small enough that tracers are conserved well enough (in particular below the pycnocline); (ii) the accelerated integration is extended by a synchronous phase of - at least - several decades (Danabasoglu et al., 1996; Wang, 2001; Danabasoglu, 2004). The synchronous extension is important not only to correctly capture oceanic variability, but also to test the stability and reliability of the accelerated equilibrium solution (cf. Bryan, 1984; see also Sect. 4.1). Previous modelling studies have demonstrated the ability of acceleration techniques to reach an equilibrium paleoclimatic solution (e.g. see Huber and Sloan, 2001; Huber and Nof, 2006).

The acceleration-induced small errors found by Danabasoglu (2004) are tolerable for most paleoclimatic applications. In particular, errors in large-scale oceanic mass and heat transports turned out to be negligible (for instance, the error in maximum Atlantic northward heat transport was about $0.01 \mathrm{PW}$ or $1-2 \%$ ). Using the same oceanic model grid as in the study by Danabasoglu (2004), a similar deep-ocean acceleration scheme is used here. The surface time step in the ocean model is set to $1 \mathrm{~h}$ (time-step restriction due to numerical instability) and does not change down to a depth of $1300 \mathrm{~m}$. Below $2500 \mathrm{~m}$, the tracer time step is increased by a factor 50 . Between $1300 \mathrm{~m}$ and $2500 \mathrm{~m}$, the tracer time step has a linear variation.

\section{Present-day control run}

\subsection{Experimental design and spin-up}

For the present-day control run of CCSM2/T31x3a, the atmospheric composition of 1990 AD is adopted. Volume mixing ratios of greenhouse gases are listed in Table 1. The total aerosol visible optical depth is set to 0.14 , while a value of $1365 \mathrm{~W} / \mathrm{m}^{2}$ is used for the solar constant. The model is initialized with observational data sets provided at www.ccsm.ucar.edu/models/ccsm2.0.1.

Using the deep-ocean acceleration technique described in the previous section, a climatic equilibrium can be achieved within a few centuries of integration. After a short (7 years) 


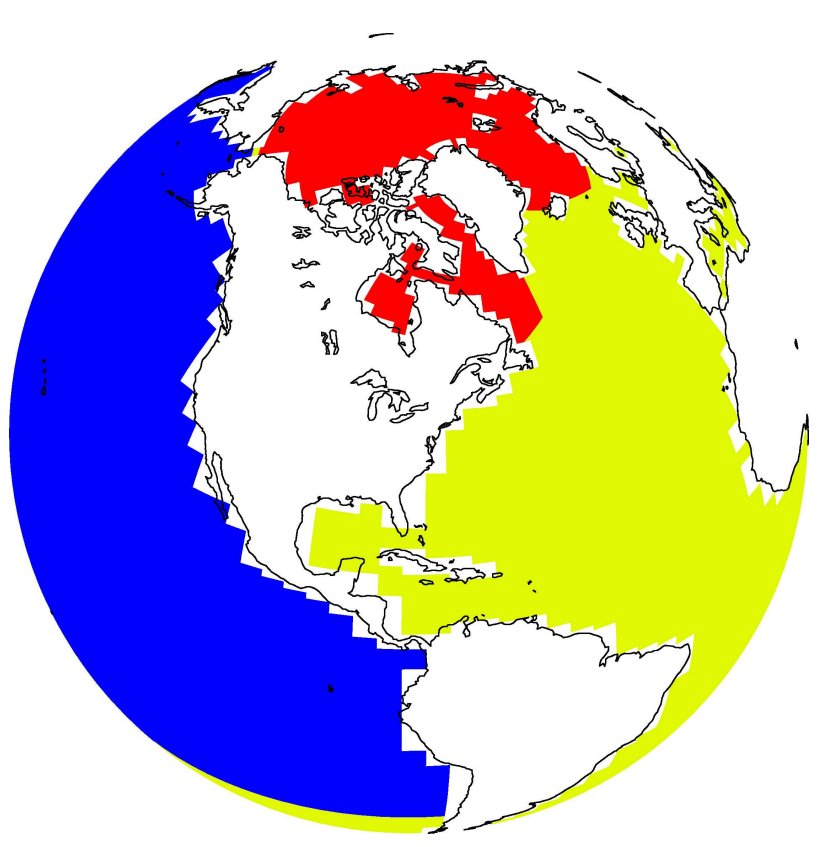

Fig. 5. Sketch of the regional freshwater flux adjustment used in CCSM2/T31x3a. Surface freshwater fluxes by precipitation and river runoff into the ocean are reduced over the red area. The corresponding amount of freshwater is distributed over the Pacific Ocean (blue area). All other parts of the world ocean (yellow area) are not affected by the flux adjustment.

Table 1. Volume mixing ratios of greenhouse gases used in the present-day control run.

\begin{tabular}{lr}
\hline Trace gas & Volume mixing ratio \\
\hline $\mathrm{CO}_{2}$ & $3.530 \times 10^{-4}$ \\
$\mathrm{CH}_{4}$ & $1.676 \times 10^{-6}$ \\
$\mathrm{~N}_{2} \mathrm{O}$ & $0.309 \times 10^{-6}$ \\
$\mathrm{CFC}_{11}$ & $0.263 \times 10^{-9}$ \\
$\mathrm{CFC}_{12}$ & $0.479 \times 10^{-9}$ \\
\hline
\end{tabular}

synchronous spin-up phase, depth-accelerated integration is applied for 293 years, followed by a centennial synchronous extension. This gives a total integration time of 400 surface years for the coupled climate model corresponding to 14,757 deep-ocean years. Only the third stage of the integration procedure (i.e. the centennial synchronous phase) shall serve for an evaluation of the simulated present-day climate.

Figure 6 shows the time series of global ocean temperature over the accelerated spin-up phase and the synchronous extension. Initialized with climatological data (Steele et al., 2001) the ocean cools by about $0.6 \mathrm{~K}$ until reaching a nearequilibrium state. During the same time, global average salinity increases by about 0.01 psu (not shown). This salin-

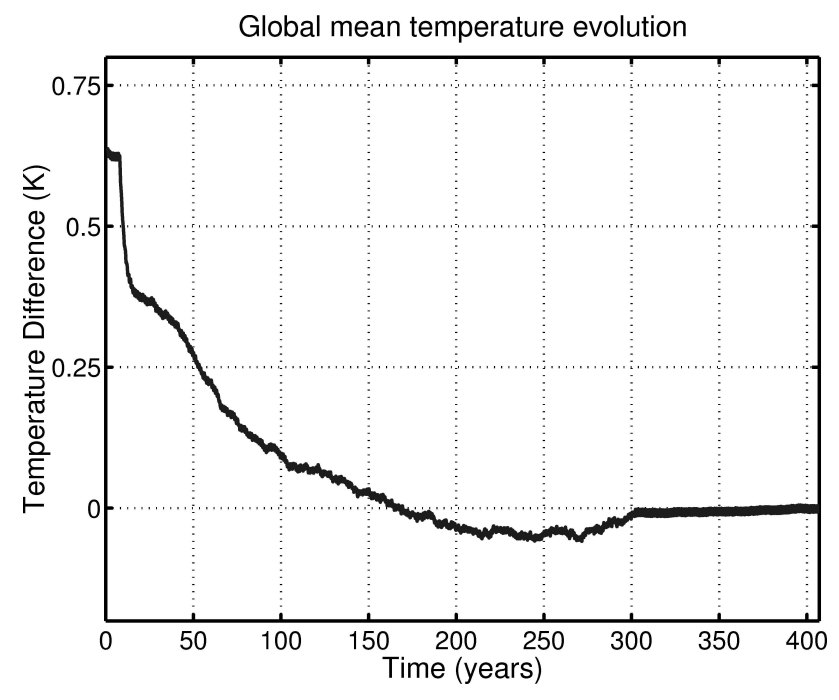

Fig. 6. Globally averaged potential temperature of the ocean during spin-up, plotted as deviation from the mean value of year 400 . Note that deep-ocean acceleration is applied from (surface) year 8 to (surface) year 300 .

Table 2. Average maximum overturning strength (AMOC) and peak northward heat transport (NAHT) in the North Atlantic, volume transport through Drake Passage (ACC), Indonesian Throughflow (ITF), and Bering Strait throughflow (BS) in CCSM2/T31x3a. For comparison, estimates given by Ganachaud and Wunsch (G\&W, 2000) and Stammer et al. (2003) are listed.

\begin{tabular}{lccc}
\hline Transport & CCSM2/T31x3a & G\&W & Stammer \\
\hline AMOC (Sv) & 14 & $13-17$ & - \\
NAHT (PW) & 0.6 & $1.15-1.45$ & 0.6 \\
ACC (Sv) & 92 & $134-146$ & 124 \\
ITF (Sv) & 10.5 & $11-21$ & 11.5 \\
BS (Sv) & 1.3 & 0.8 & - \\
\hline
\end{tabular}

ity drift is mainly attributable to the non-conservative character of deep-ocean acceleration.

The Hovmöller diagrams in Fig. 7 display the time evolution of zonally and meridionally averaged potential temperature and salinity for the Atlantic, Pacific, and Indian oceans. It is clearly visible that the global oceanic cooling (Fig. 6) can be ascribed to a decrease in deep and bottom water temperatures, while the upper layers gradually warm during the spinup. The abyssal potential temperature drift during the last century of accelerated integration (i.e. between surface year 200 and 300) is below $0.1 \mathrm{~K}$, i.e. smaller than $2 \times 10^{-5} \mathrm{~K}$ per deep-water year. For the same time interval, abyssal salinity changes are about 0.03 psu or $6 \times 10^{-6}$ psu per deep-water year. These rates are sufficiently small, confirming that the climatic state is at equilibrium for practical purposes at the end of the accelerated spin-up phase. 

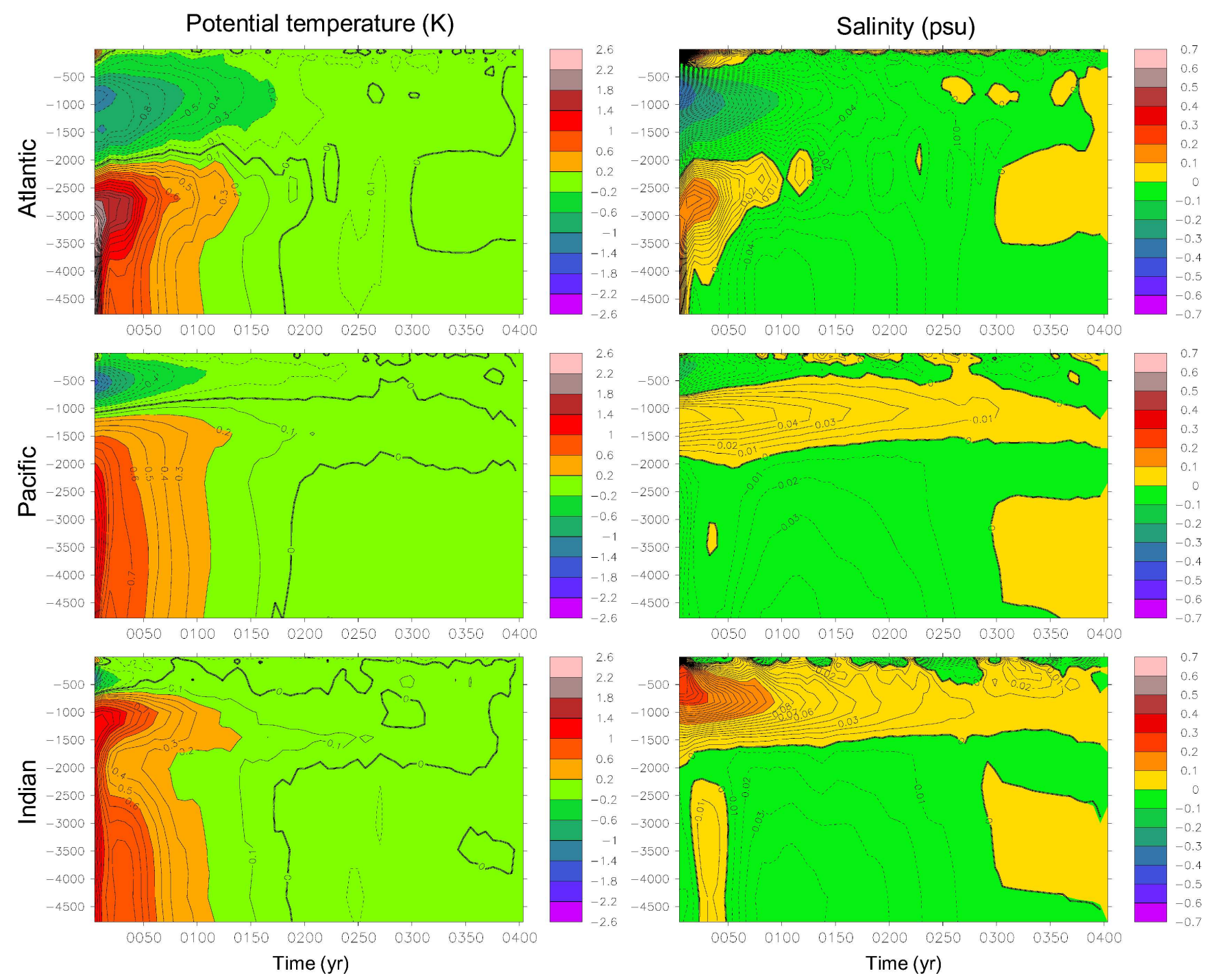

Fig. 7. Time versus depth (m) plots of horizontally averaged potential temperatures (left) and salinities (right) for the Atlantic, Pacific, and Indian Ocean basins, plotted as deviations from the mean value of year 400 (smoothed by 7 -yr averaging). Contour intervals are $0.1 \mathrm{~K}$ and $0.01 \mathrm{psu}$, respectively. Note that deep-ocean acceleration is applied from (surface) year 8 to (surface) year 300 .

Starting from an ocean at rest, most mass (or volume) transports obtain quasi-equilibrium within 50 surface years. Figure 8 shows the temporal evolution of the Atlantic meridional overturning streamfunction at $25^{\circ} \mathrm{S}$. At equilibrium, almost $12 \mathrm{~Sv}$ of deep water are exported to the Southern Ocean between 1000 and $3000 \mathrm{~m}$ depth; below $3000 \mathrm{~m}, 2-3 \mathrm{~Sv}$ of Antarctic Bottom Water (AABW) enter the Atlantic Ocean. The major goal of model tuning is achieved: CCSM2/T31x3a produces a robust AMOC which induces a substantial northward heat transport (cf. Sect. 4.2.1). In this stable climatic mode, the northern high-latitude freshwater flux correction totals $0.107 \mathrm{~Sv}$ (averaged over the last 100 years of the integration period); $69 \%$ (i.e. $0.074 \mathrm{~Sv}$ ) of this amount is due to river runoff, while $31 \%$ (i.e. $0.034 \mathrm{~Sv}$ ) is due to precipitation over the ocean. For comparison: Actual climatological river discharge into the Arctic Ocean is about 0.1 Sv (e.g. Prange and Gerdes, 2006).

The largest transport of water in the world ocean occurs within the Antarctic Circumpolar Current (ACC). The volume transport through Drake Passage rapidly equilibrates during model spin-up approaching $90 \mathrm{~Sv}$ (Fig. 9). It is important to note that the time series of oceanic volume transports provide a hint on the stability and reliability of the accelerated equilibrium solution (cf. Peltier and Solheim, 2004). Large-scale volume transports (like the meridional overturning circulation or the ACC) quickly respond to changes in the forcing, generally adjusting within a few decades (e.g. Gerdes and Koeberle, 1995; Danabasoglu et al., 1996). If the 


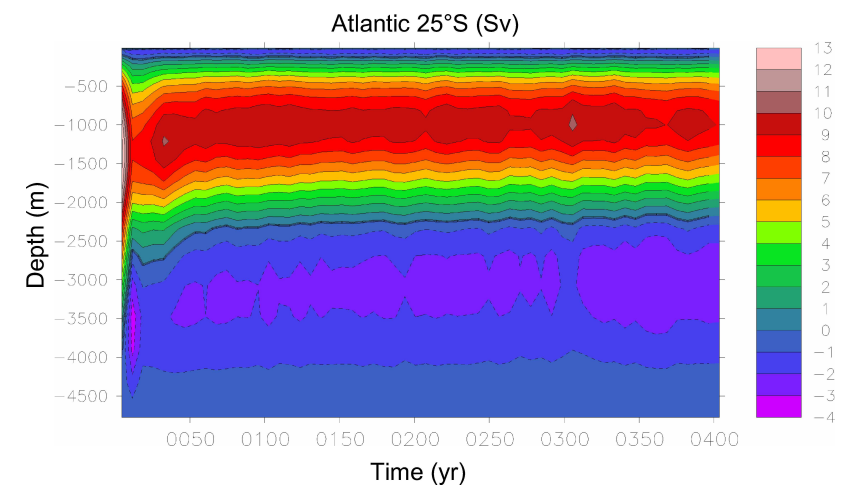

Fig. 8. Time versus depth plot of the meridional overturning streamfunction in the South Atlantic during spin-up (smoothed by 7 -yr averaging). Note that deep-ocean acceleration is applied from (surface) year 8 to (surface) year 300 .

accelerated integration led to a "false equilibrium", a rapid reorganisation of the oceanic volume transports would be expected after switching from accelerated to synchronous integration at year 300 (which is obviously not the case).

\subsection{Equilibrium climatology}

\subsubsection{Ocean}

For the following evaluation of the CCSM2/T31 3 a presentday climatic equilibrium, the last 90 years of the synchronous integration phase are considered; that is, averages from surface years 311-400 are calculated and compared to observational climatologies or observation-based estimates.

Some important integrated measures for the world ocean circulation are listed in Table 2 and compared with estimates from inverse (Ganachaud and Wunsch, 2000) and dataconstrained (Stammer et al., 2003) modelling. While the Indonesian Througflow (ITF) and the transport of Pacific Water into the Arctic Ocean through Bering Strait (cf. Sect. 2) are well captured by the model, the simulated mass transport of the ACC is $25-30 \%$ smaller than observation-based estimates. Without further sensitivity studies one can only speculate on the reasons for this bias. The transport of the ACC is usually dominated by the baroclinic flow field (e.g. Webb and de Cuevas, 2007). Thus, the undersimulated ACC transport is probably a result of an incorrect baroclinic field in the Southern Ocean that may result from too weak zonal wind forcing at ACC latitudes (cf. Sect. 4.2.3).

The maximum meridional overturning strength in the North Atlantic appears to be in line with observation-based estimates. Note, however, that only $60 \%$ of deep-water formed in the North Atlantic is exported to the Southern Ocean (Fig. 10). Accordingly, the Atlantic Ocean northward heat transport simulated by CCSM2/T31x3a is at the lower end of the range suggested by observations. In addition, the

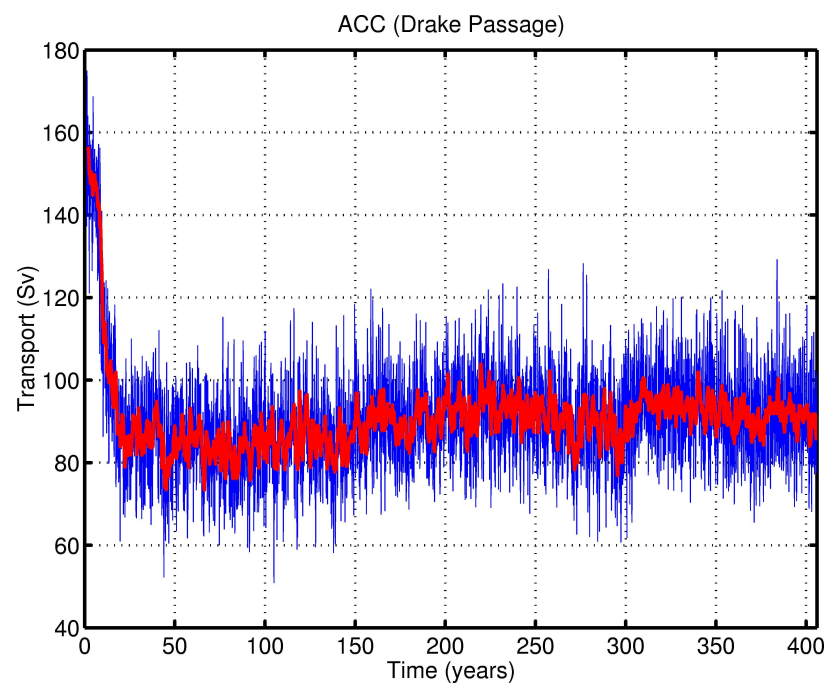

Fig. 9. Monthly (blue) and annual-mean (red) transport time series for the Antarctic Circumpolar Current at Drake Passage. Note that deep-ocean acceleration is applied from (surface) year 8 to (surface) year 300 .

flow of NADW is relatively shallow and the total formation of AABW is weak (Fig. 10). For comparison: Ganachaud and Wunsch (2000) estimate a northward AABW flow of 5$7 \mathrm{~Sv}$ into the Atlantic, 4-12 Sv into the Indian, and 5-9 Sv into the Pacific Ocean.

A rather unusual feature of CCSM2/T31x3a's NADW overturning cell is the strong sinking around $40^{\circ} \mathrm{N}$ in addition to the common sinking branch around $60^{\circ} \mathrm{N}$ (cf. Stouffer et al., 2006). A quite similar pattern is produced by CCSM3/T31 (cf. Yeager et al., 2006). Showing vertical velocities at $750 \mathrm{~m}$ depth in the North Atlantic, Fig. 11 provides some insight into the three-dimensional structure of the overturning circulation. It is clearly visible that the mid-latitude sinking branch of the AMOC is associated with a wide area of downward motion along the path of the North Atlantic Current. It is unclear why other models show this behaviour only to a lesser extent or not at all. Surface heat fluxes and oceanic mixing processes are likely to play a role. However, extensive sensitivity studies were required to better define and resolve this problem.

The horizontal distribution of ocean mean currents is displayed in Fig. 12. In the surface layer, the equatorial Pacific is dominated by Ekman-driven divergent flow. At $100 \mathrm{~m}$ depth, swift equatorial undercurrents, flowing eastward, are visible in all three oceans. In the Pacific Ocean, the Equatorial Undercurrent is supplied by meridional geostrophic inflow that compensates the Ekman transports, including inflows at the western boundary. In the Indian Ocean, the eastward current is mainly fed by the South Equatorial Current which, in turn, is supplied by the subtropical gyre circulation and the ITF. In accordance with observations, the ITF 
receives water basically from the Pacific North Equatorial Current (cf. Gordon, 2001). The Atlantic Equatorial Undercurrent is mainly fed from the South Atlantic (South Equatorial Current).

The Benguela Current, appearing below the Ekman layer, separates from the African coast far too south. Similar problems arise with other eastern boundary currents (e.g. the Humboldt Current). Given the rather coarse resolution of the model grid, subtropical western boundary currents - including Kuroshio, Gulf Stream, East Australian Current, Mozambique Current, and Brazil Current - are simulated satisfactorily. As in reality, the Brazil Current is conspicuously weak as compared with the other western boundary currents (cf. Peterson and Stramma, 1991).

At high southern latitudes, the flow field is dominated by the ACC. South of the ACC, the westward flowing Antarctic Coastal Current is simulated. Around the southern tip of Africa, the model version of the Agulhas Current/leakage transports water from the Indian Ocean to the South Atlantic. This transport may be an integral part of the global conveyor belt circulation (Gordon, 1986). In the North Atlantic, a strong North Atlantic Current marks the boundary between the subtropical gyre and the cyclonic subpolar gyre. Providing the convective regions south of Greenland and in the Nordic Seas with warm and salty water, the simulation of the North Atlantic Current is of utmost importance for the thermohaline circulation.

The flow field at $2000 \mathrm{~m}$ depth is characterized by a vigorous circulation around Antarctica. In the Atlantic Ocean, the southward movement of NADW constitutes the lower limb of the thermohaline overturning circulation. The NADW flow path forms an anticyclonic loop in the North Atlantic, which has no counterpart in observations. South of $30^{\circ} \mathrm{N}$, the southward flow of NADW is confined to the Deep Western Boundary Current.

Potential temperatures simulated by CCSM2/T31x3a are shown in Fig. 13 along with observational data. Modelled sea surface temperatures (SST) in the tropical Indian and Pacific oceans are lower than observed. This cold bias is up to $2 \mathrm{~K}$ in the equatorial central Pacific (see also Fig. 28). The cold surface temperatures are associated with a larger than observed low-level cloud cover over the equatorial Pacific (not shown). In the tropical Atlantic, the western warm pool is too cold and the zonal SST gradient has the wrong sign. The tropical cold temperature bias is also visible at $100 \mathrm{~m}$ depth. The most pronounced deficiencies at subtropical latitudes are found in the eastern boundary currents and major upwelling regions (along the west coasts of North America, South America, northwest Africa, and southwest Africa), where surface and subsurface temperatures are too warm. In northern high latitudes, the North Atlantic Current provides for moderate water temperatures south of Iceland and in the Norwegian Sea. Compared to the standard CCSM2/T31 control run (not shown), the model adjustments result in upper-ocean temperatures in the northern North Atlantic that are much more in
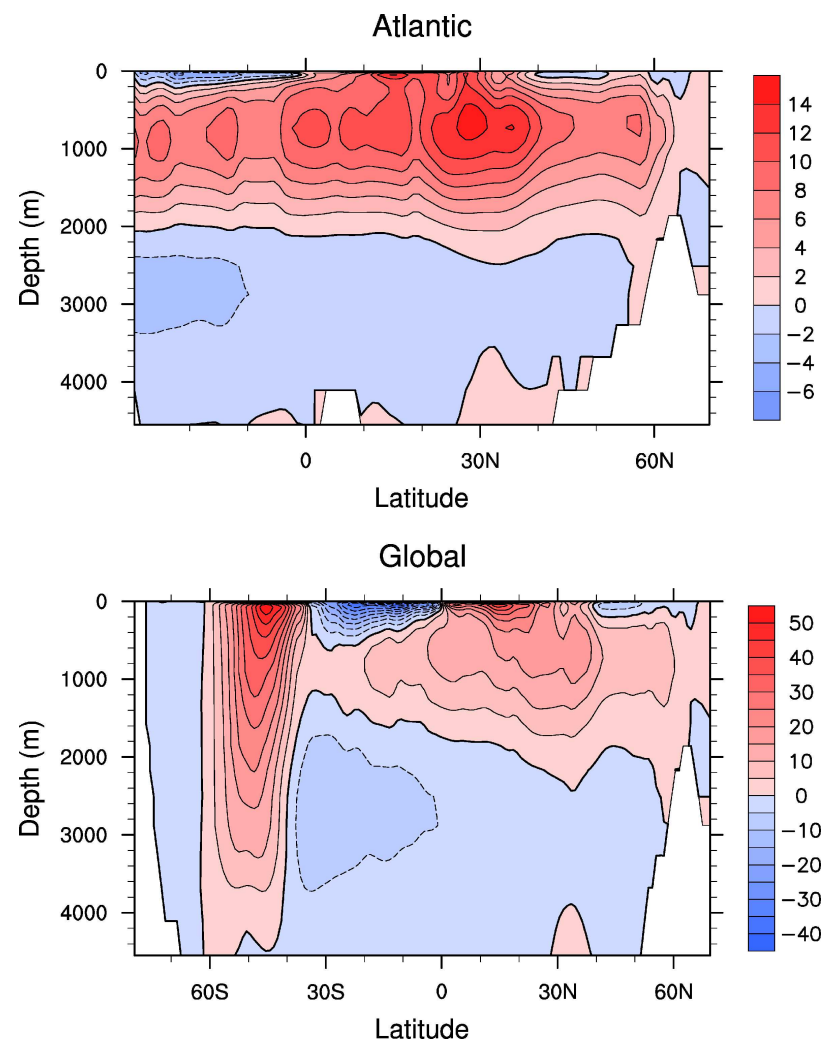

Fig. 10. Mean Atlantic (top) and global (bottom) Eulerian meridional overturning circulation (Sv). Positive values indicate clockwise circulation. Since only the Eulerian portion of the circulation is shown, a spurious wind-driven overturning cell (so-called Deacon cell) appears in the ACC region (Southern Ocean). As documented by Danabasoglu et al. (1994), there is a substantial cancellation between the Eulerian and bolus velocity terms in the Lagrangian tracer velocity for the ACC region when using the GentMcWilliams isopycnal scheme as in CCSM2/T31x3a (not shown here).

line with observations. At $500 \mathrm{~m}$ depth, the modelled Pacific, Indian and North Atlantic subtropical gyres exhibit higher temperatures compared to observations, whereas the subtropical South Atlantic is slightly too cold in CCSM2/T31x3a. At $2000 \mathrm{~m}$ in the North Atlantic, simulated NADW has a potential temperature of about $4.5^{\circ} \mathrm{C}$. Deep temperatures in the Pacific and Indian oceans are $\sim 1 \mathrm{~K}$ colder than in observations, pointing to a cold bias in AABW. A similar deep-ocean cold bias has been found in a higher resolution version of the model (Kiehl and Gent, 2004).

Figure 14 shows global salinity fields. The success of the CCSM2/T31x3a model adjustments is most evident when comparing the field of annual-mean sea surface salinity with that from the standard CCSM2/T31 control run (Fig. 2). The entire North Atlantic, including subtropical and subpolar regions as well as the Nordic Seas and the Arctic Ocean, 


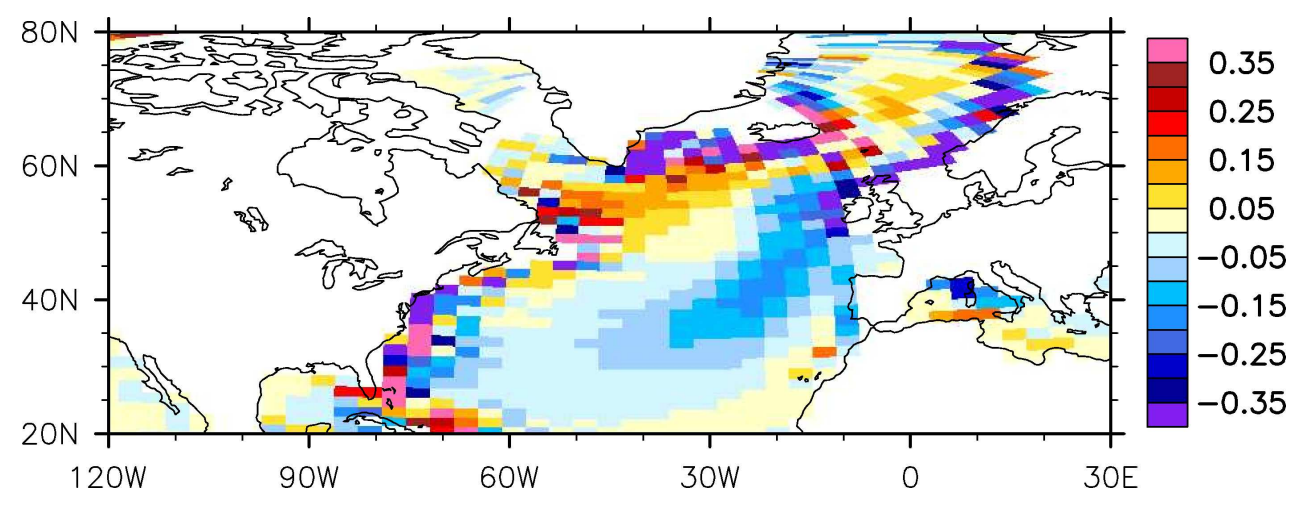

Fig. 11. Annual-mean ocean vertical velocities (m/day) at $750 \mathrm{~m}$ depth in the North Atlantic (positive values indicate upward flow).

exhibits surface salinities which are now much closer to observations. However, low-salinity water still caps off the Labrador Sea (cf. Fig. 28), forcing convection to occur further to the east. The reason for this shortcoming is unclear. Deficiencies in the wind stress curl, however, are likely to play a crucial role in the formation of the Labrador lowsalinity cap (Gnanadesikan et al., 2006). In the Nordic Seas and northern North Atlantic, winter convection and, hence, deep-water formation takes place where upper-ocean salinities are around or above 35 psu.

In the South Atlantic, the model exhibits an upper-ocean fresh bias. The subtropical front is marked by the $34.9 \mathrm{psu}$ isohaline at $100 \mathrm{~m}$ depth. In observations, the front resides well to the south of the Cape of Good Hope and the Australian continent. In CCSM2/T31x3a, the subtropical front is shifted far to the north (cf. Fig. 14). Part of this fresh bias can be attributed to excessive rainfall between $35^{\circ} \mathrm{S}$ and $60^{\circ} \mathrm{S}$ (see Fig. 21). In the southeastern Atlantic, a possible source of error is the lack of Agulhas eddies that transport salty water into the Atlantic. A much finer grid resolution would be required to simulate the formation of these eddies.

Relatively high salinities are found in the North Pacific, whereas the upper Indian Ocean is overly fresh. In particular, the salinity of Australasian Mediterranean Water (AAMW) at the surface (at $100 \mathrm{~m}$ depth) is about $1 \mathrm{psu}(0.5 \mathrm{psu})$ below observational values. At $500 \mathrm{~m}$ depth, the signature of AAMW is well captured by the model, still the region around Madagascar is too fresh. The salinity field at $2000 \mathrm{~m}$ reveals somewhat saltier NADW in the model compared to observations. Traces of Eurafrican Mediterranean Water are absent at $2000 \mathrm{~m}$ depth in both the temperature (Fig. 13) and salinity (Fig. 14) fields of the model.

\subsubsection{Sea ice}

Maximum and minimum sea-ice conditions in the Northern and Southern Hemispheres simulated by CCSM2/T31x3a are displayed in Fig. 15. The use of optimized sea-ice/snow albedos in CCSM2/T31x3a leads to an ice thickness of 2.5$3.5 \mathrm{~m}$ over the central Arctic Ocean. North of Greenland the sea-ice thickness increases to about $5 \mathrm{~m}$. These numbers are in good agreement with upward-looking sonar observations (e.g. Bourke and Garrett, 1987; Rothrock et al., 2003) and satellite altimeter measurements (Laxon et al., 2003). In the Arctic Ocean proper, the largest discrepancy between model and data is found along the East Siberian coast, where the model predicts ice thicknesses similar to those north of Greenland, while observations suggest thin ice $(<1 \mathrm{~m})$ or even ice-free conditions during specific summer months. The overly thick ice cover along the East Siberian coast can mainly be attributed to a deficient wind-stress forcing. A negative sea-level pressure (SLP) bias over Alaska and northwestern Canada (cf. Fig. 18) forces sea ice to drift from the North American coast towards East Siberia, thus maintaining an unusually thick ice-cover in that region. In the North Atlantic and the Nordic Seas, the model produces too much ice area. Most severly affected in winter are the Labrador Sea, the regions east and northeast of Iceland, the sector south of Svalbard as well as the western Barents Sea. The model reproduces year-round ice-free conditions over almost the entire Norwegian Sea. During the summer months, CCSM2/T31x3a simulates too much sea ice south of Greenland, around Svalbard, and in Baffin Bay. In the Southern Ocean, the overall pattern of sea-ice cover is simulated satisfactorily. Apart from an excessively thick ice cover along the eastern coast of the Antarctic Peninsula, simulated ice thicknesses are rather close to (the few available) observations, especially during the cold season (cf. Strass and Fahrbach, 1998; Harms et al., 2001). As in the Northern Hemisphere, however, CCSM2/T31x3a exhibits a bias towards extensive sea-ice cover in the Atlantic sector. This is particularly true for the Scotia Sea. A closer inspection of the annual cycle reveals that - in both hemispheres - the simulation skill of sea-ice thickness is higher during the respective winters than during the summer periods which are characterized by largerthan-observed ice thicknesses (cf. Fig. 15). 


\subsubsection{Atmosphere}

The overall performance of CCSM2/T31x3a with respect to the climatology of atmospheric basic surface variables (SLP, reference height air temperature, precipitation) is described in the following. Figure 16 displays the geographical mean pattern of December-February (DJF) SLP simulated by the model against NCEP reanalysis data. The core positions of subpolar lows and subtropical highs are generally well captured in CCSM2/T31x3a, although the centers of the Icelandic Low and Azores High are slightly displaced eastward relative to observations. The strengths of the subtropical highs are overestimated in the Northern Hemisphere, and underestimated in the Southern Hemisphere. Anomalously high pressure is found in Arctic and sub-Arctic regions, where the model produces too much sea ice and too cold surface air temperatures (Labrador Sea, Greenland Sea, Barents Sea). Over Canada, the simulated winter pressure is lower than observed by up to $9 \mathrm{hPa}$. In high southern latitudes, the model exhibits a low pressure-bias over the subpolar seas, and a high-pressure bias over the Antarctic continent.

During June-August (JJA) the simulated strengths of subtropical highs are close to reanalysis data in the Southern Hemisphere (Fig. 17). In the Northern Hemisphere, CCSM2/T31x3a exhibits a pronounced high-pressure bias over the mid-latitude oceans. In the Arctic realm, the simulated SLP is more than $6 \mathrm{hPa}$ larger than in NCEP data with a maximum deviation over Greenland. Antarctic and subAntarctic regions in the model climate are characterized by a strong low-pressure bias relative to reanalysis data. A similar seasonality of the Antarctic SLP bias (high pressure during DJF, low pressure during JJA) has been found in other climate models (e.g. Min et al., 2004). It should be noted, however, that errors in the reanalysis data cannot be excluded for these extreme regions.

The deviation in simulated annual-mean SLP (Fig. 18) is associated with anomalously weak westerlies at the latitude of Drake Passage relative to NCEP data. The poor simulation of Southern Ocean wind forcing may partly be responsible for the low volume transport in the ACC (see above). Moreover, it may partly account for the model's bias towards a weak AMOC (cf. McDermott, 1996; Gnanadesikan, 1999).

The geographical pattern of DJF 2-meter air temperature over land is shown in Fig. 19. The winter surface climate of CCSM2/T31x3a is too warm over Greenland, northeastern Asia, and northern North America. The North American warm bias is associated with a low SLP anomaly (Fig. 16). During the summer season, simulated air temperatures are in better agreement with observations (Fig. 20). An overall cold bias for African and South American climates, however, is visible in both seasons. The same holds true for a pronounced warm bias over Antarctica.

A comparison of the simulated geographical distribution of annual-mean precipitation rate with CMAP observations
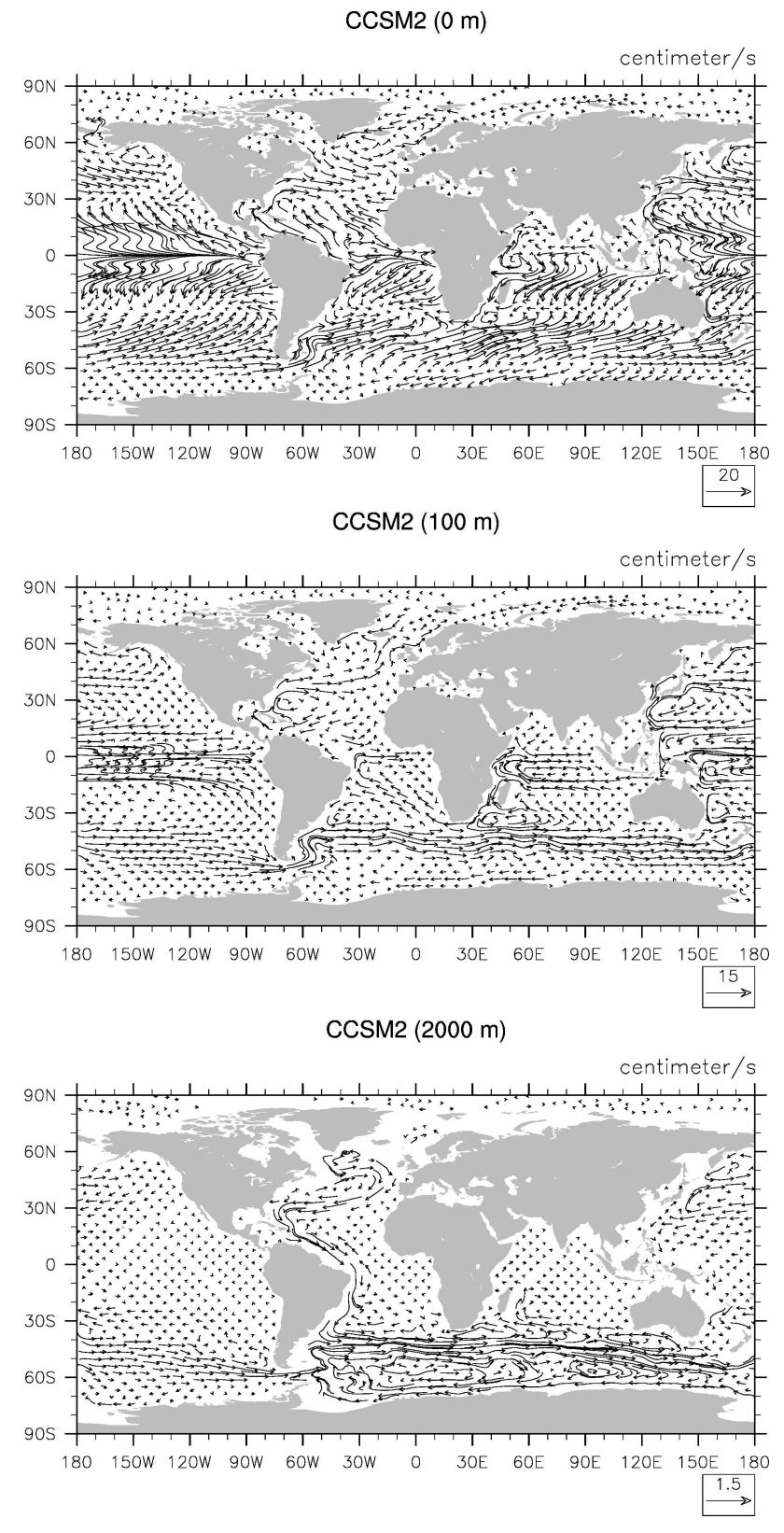

Fig. 12. Annual-mean ocean velocities at the surface (top), at $100 \mathrm{~m}$ depth (middle), and at $2000 \mathrm{~m}$ depth (bottom).

is displayed in Fig. 21. The warm-biased region of northwestern North America receives excessive precipitation in CCSM2/T31x3a. The same holds for northeastern Siberia, albeit with a smaller magnitude of the error. Pronounced wet biases are also visible over the central and southern parts of Africa, northern China, southern India, and eastern Indonesia, while Mainland Southeast Asia is too dry in the model. On the eastern side of the tropical Pacific, the model underestimates precipitation over central America 

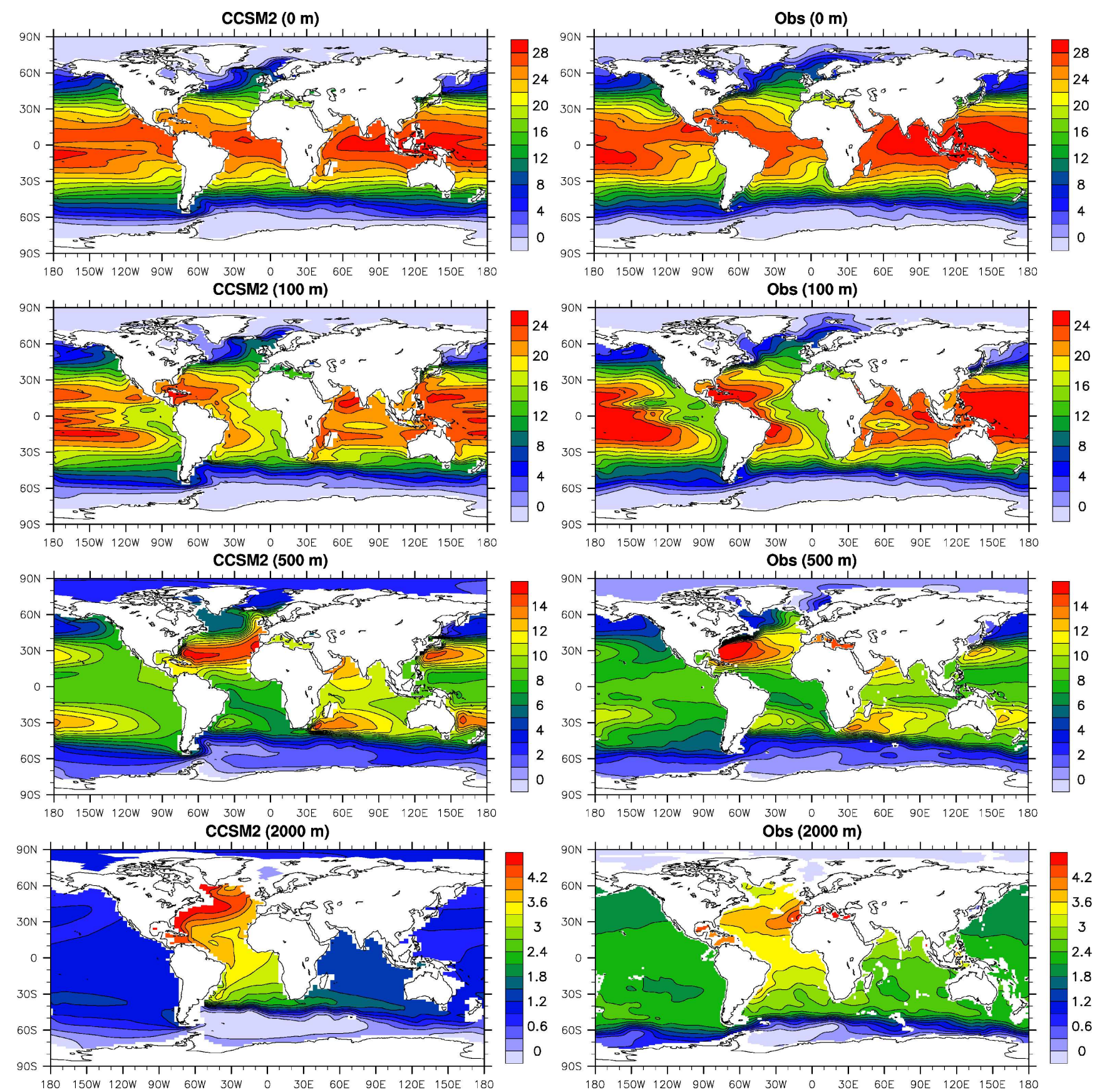

Fig. 13. Annual-mean ocean temperature $\left({ }^{\circ} \mathrm{C}\right)$ at different depths simulated by CCSM2/T31x3a (left) and from Levitus data (right).

and northern South America, while the coastal areas of Peru and Ecuador are too wet. Over the tropical ocean, the difference plot between model and data reveals several shortcomings in the simulation: an east-west dipole over the Indian Ocean, a north-south dipole over the equatorial Atlantic owing to a rather diffuse Atlantic Intertropical Convergence Zone (ITCZ) in the model annual average, and a "double
ITCZ" in the eastern Pacific. The "double ITCZ" emerges from a spurious zonal band of excess rainfall just south of the equator, whereas the observations reveal a maximum extending from the west Pacific warm pool south-eastwards towards French Polynesia (the South Pacific Convergence Zone).

Figure 22 shows the mean annual cycle of zonally averaged precipitation as derived from the model and CMAP 

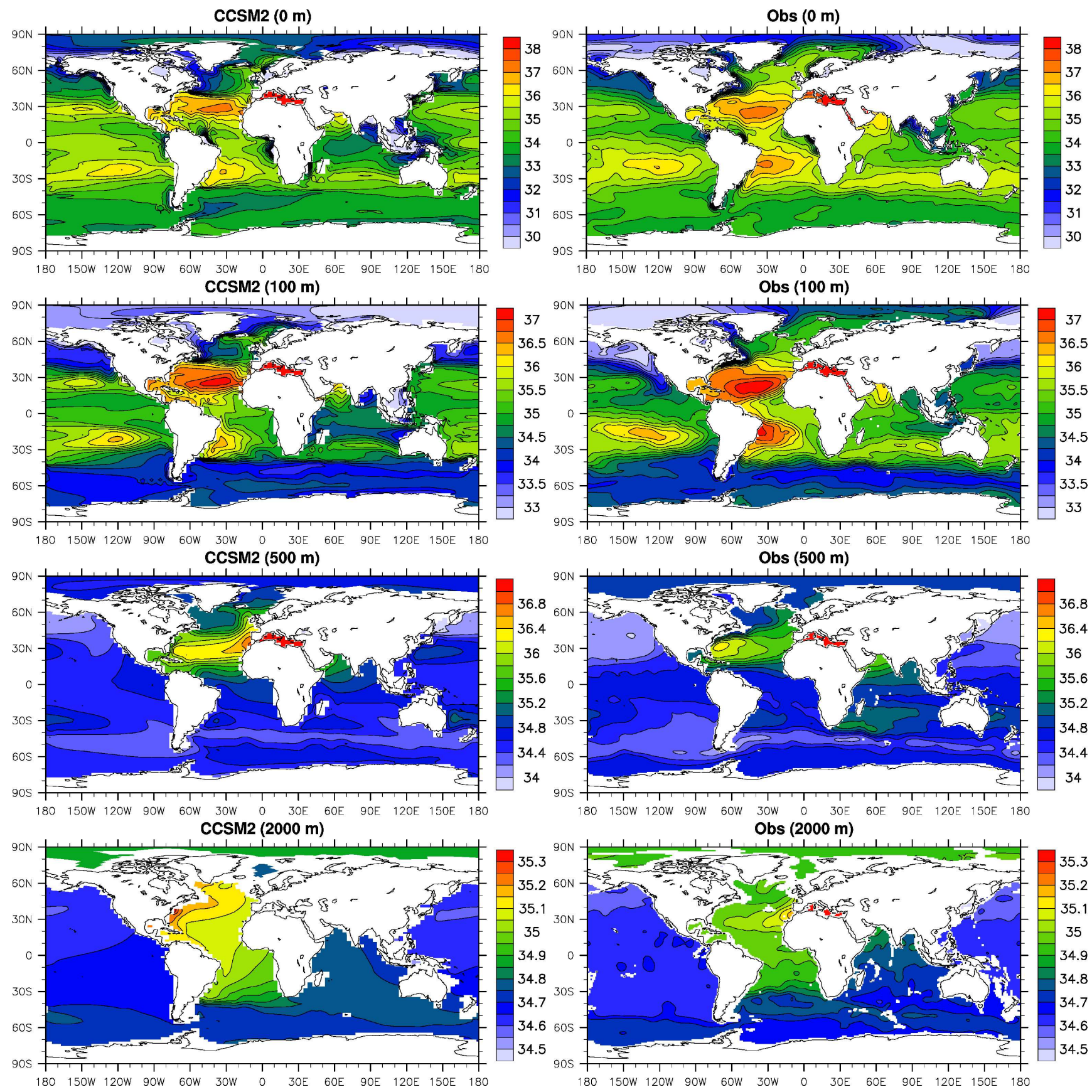

Fig. 14. Annual-mean ocean salinity (psu) at different depths simulated by CCSM2/T31x3a (left) and from Levitus data (right).

data. While the major meridional shift in observed tropical precipitation from the southern to the Northern Hemisphere takes place from March to April, it occurs between May and July in the model. During that time, zonal-average CCSM2/T31 3 a precipitation shows a false double structure of the ITCZ. In observations, the zonally averaged precipitation rate has a Northern Hemisphere maximum from June to August. In the model, the Northern Hemisphere maximum occurs in September and is somewhat smaller than observed. In Northern Hemisphere mid-latitudes, the seasonal variation of precipitation is overestimated by the model. In the Southern Hemisphere, CCSM2/T31x3a has a year-round dry bias around $30^{\circ} \mathrm{S}$, and a wet bias around $50^{\circ} \mathrm{S}$ (see also Fig. 21). 
$\operatorname{March}(\mathrm{NH})$

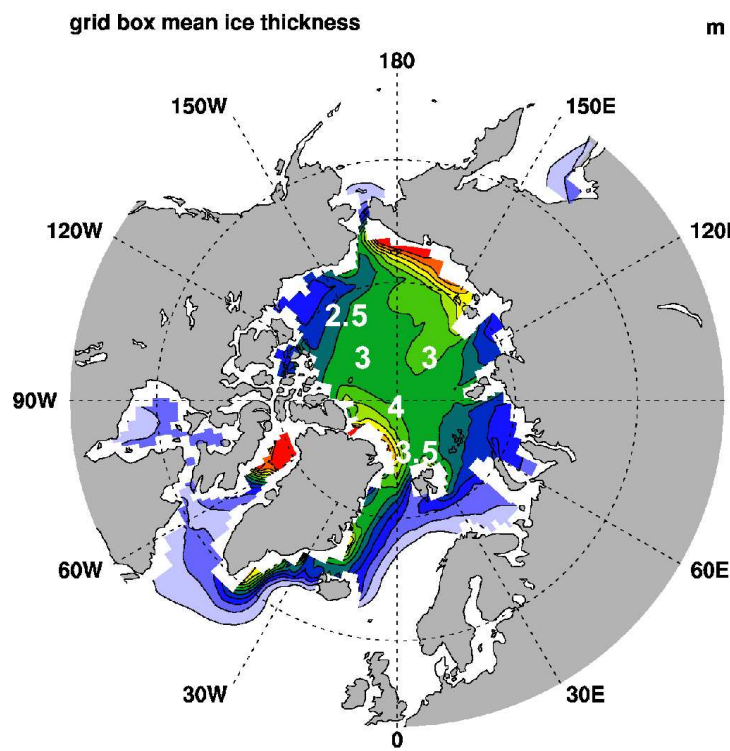

September (NH)

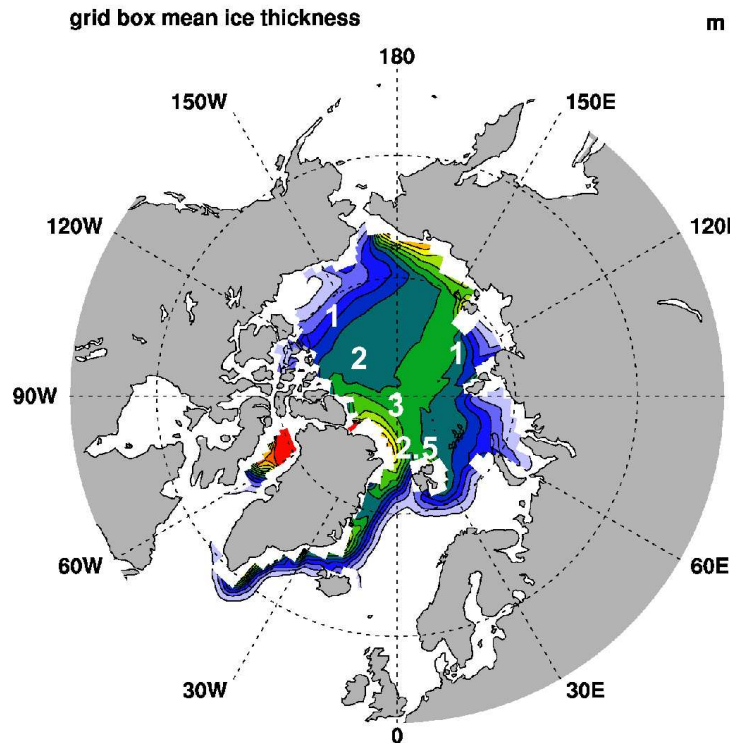

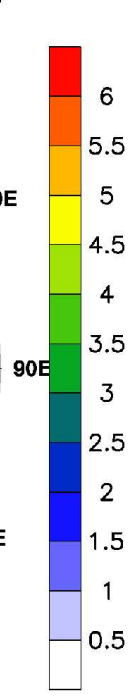

September (SH)

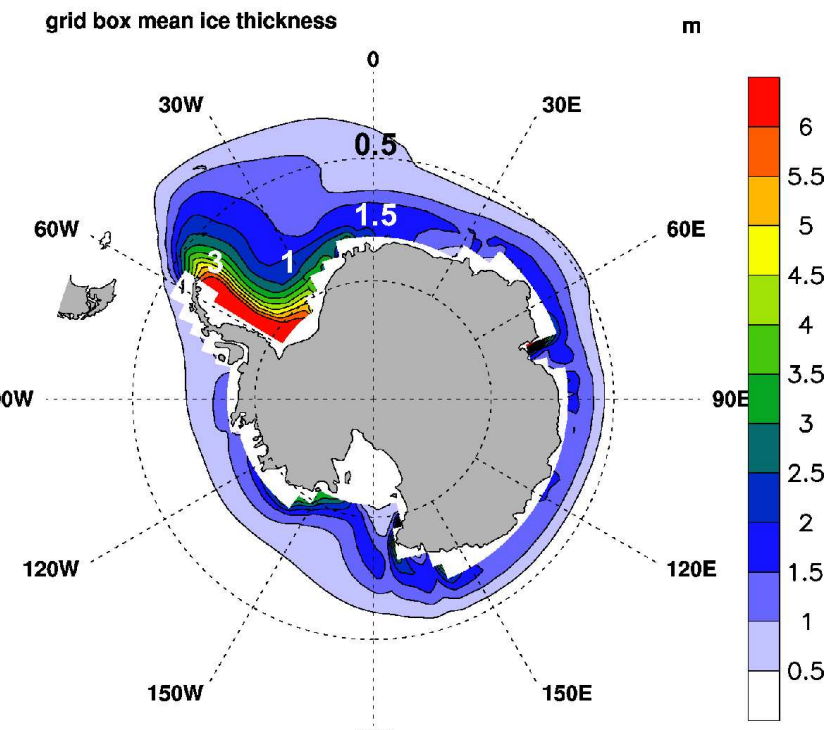

180

March (SH)

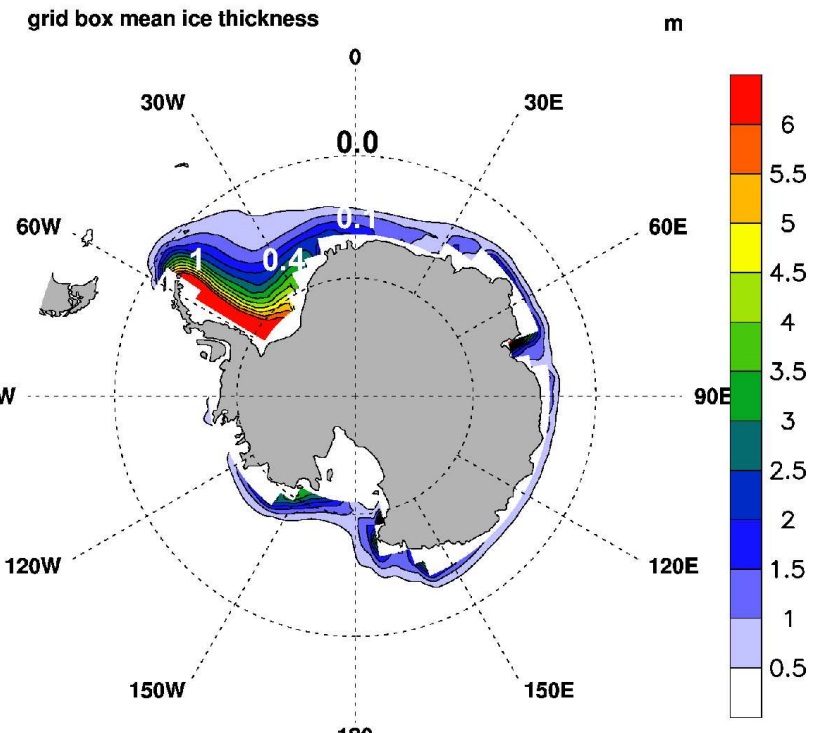

Fig. 15. Sea-ice thickness during months of maximum (top) and minimum (bottom) ice cover for the Arctic (left) and Antarctic (right). Numbers mark ice thicknesses based on observations (Strass and Fahrbach, 1998; Harms et al., 2001; Rothrock et al., 2003).

\subsubsection{Total heat transport}

Annual averaged meridional heat transports by the ocean, the atmosphere, and the coupled system are displayed in Fig. 23 and compared with NCEP-derived values. In CCSM2/T31 3 a, the maximum meridional ocean heat transport is $1.3 \mathrm{PW}$ in the Northern Hemisphere, and 1.2 PW in the Southern Hemisphere. These transports are about 0.5 PW smaller than NCEP-derived values. Maximum meridional heat transports in the atmosphere model are $4.9 \mathrm{PW}$ and 5.4 PW in the Northern and Southern Hemisphere, respectively. While the Northern-Hemisphere value is in good agreement with reanalysis, the Southern Hemisphere atmospheric transport is about $0.5 \mathrm{PW}$ larger than the NCEPderived value. 
CCSM2 (yrs 311-400)
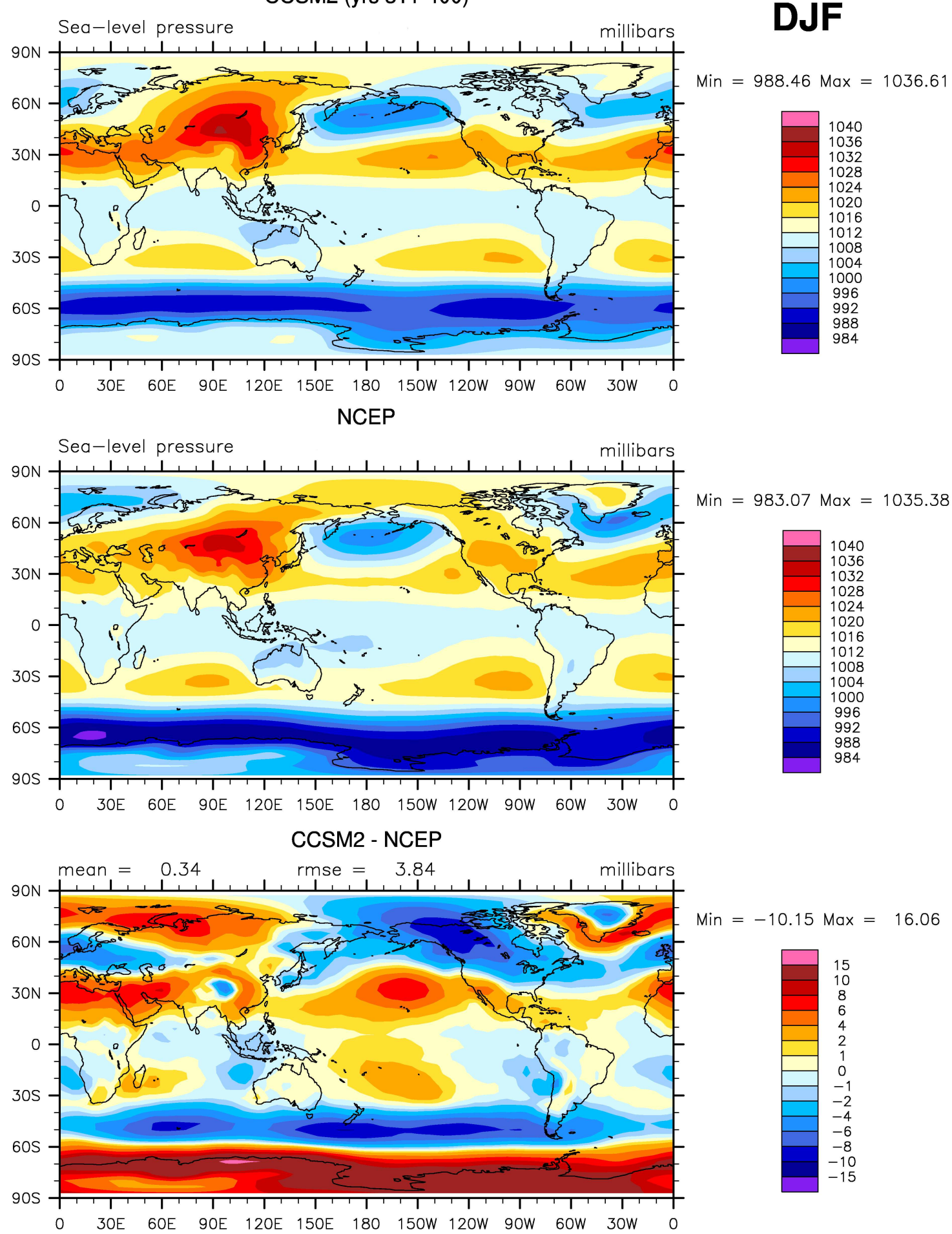

Fig. 16. December-February (DJF) mean sea-level pressure: CCSM2/T31x3a control run versus NCEP 1979-1998 reanalysis data $($ rmse $=$ root-mean-square error). 

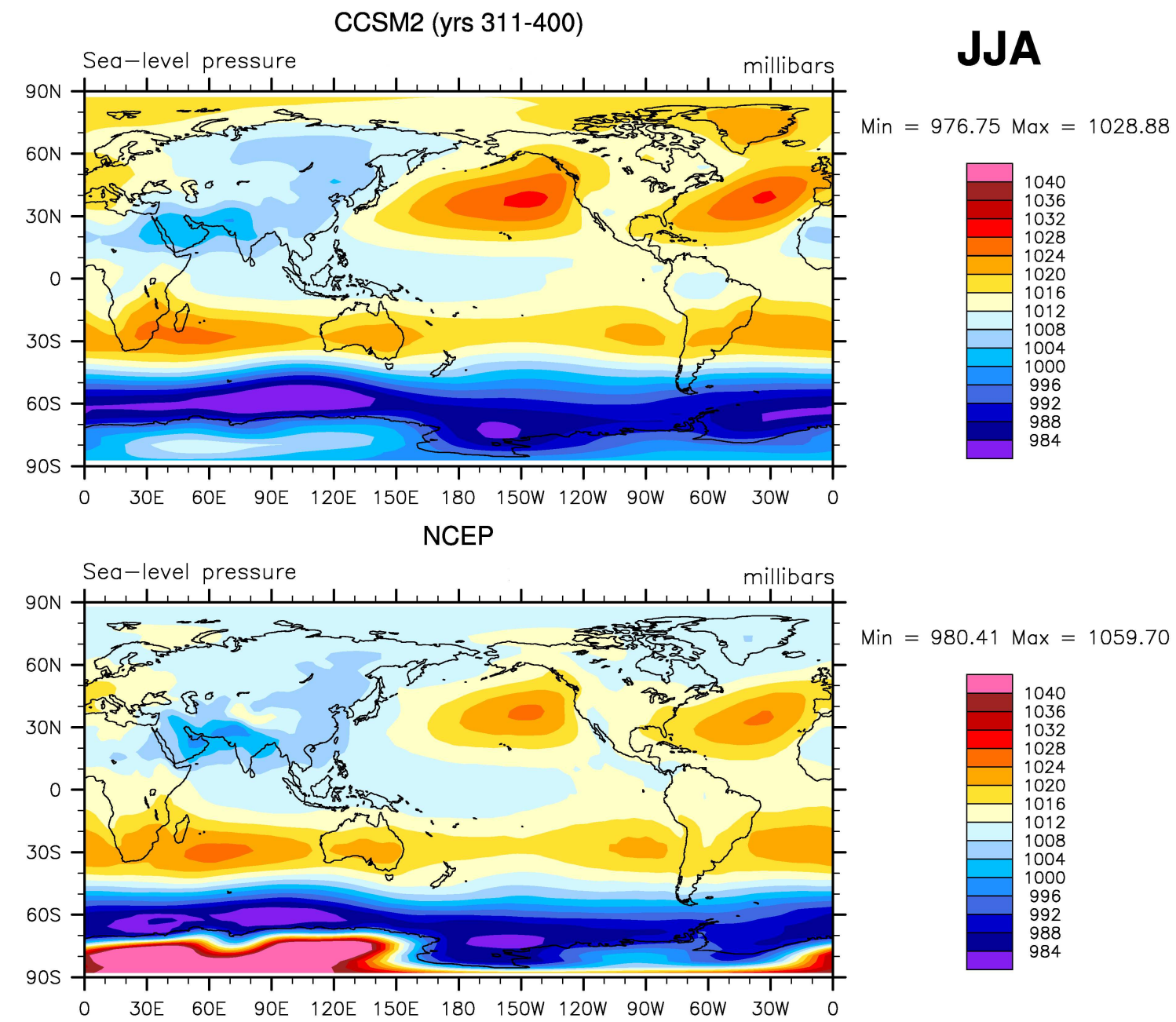

\section{CCSM2 - NCEP}

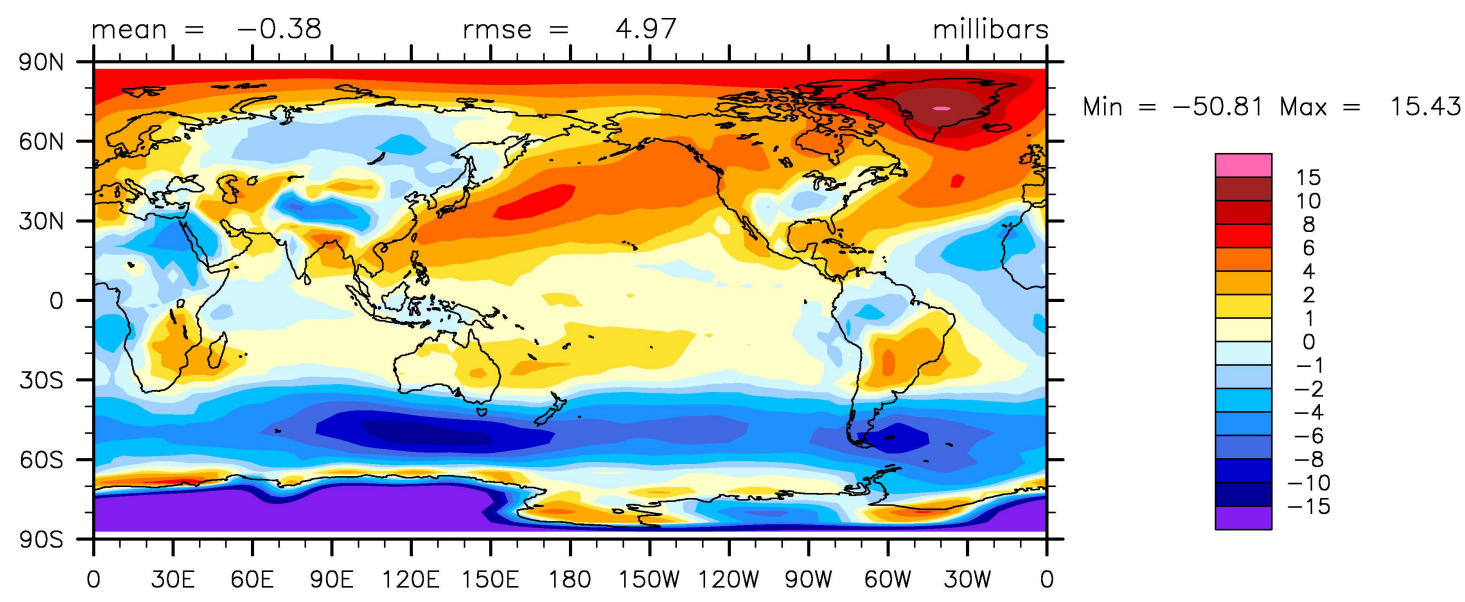

Fig. 17. June-August (JJA) mean sea-level pressure: CCSM2/T31 x3a control run versus NCEP 1979-1998 reanalysis data $($ rmse $=$ rootmean-square error). 


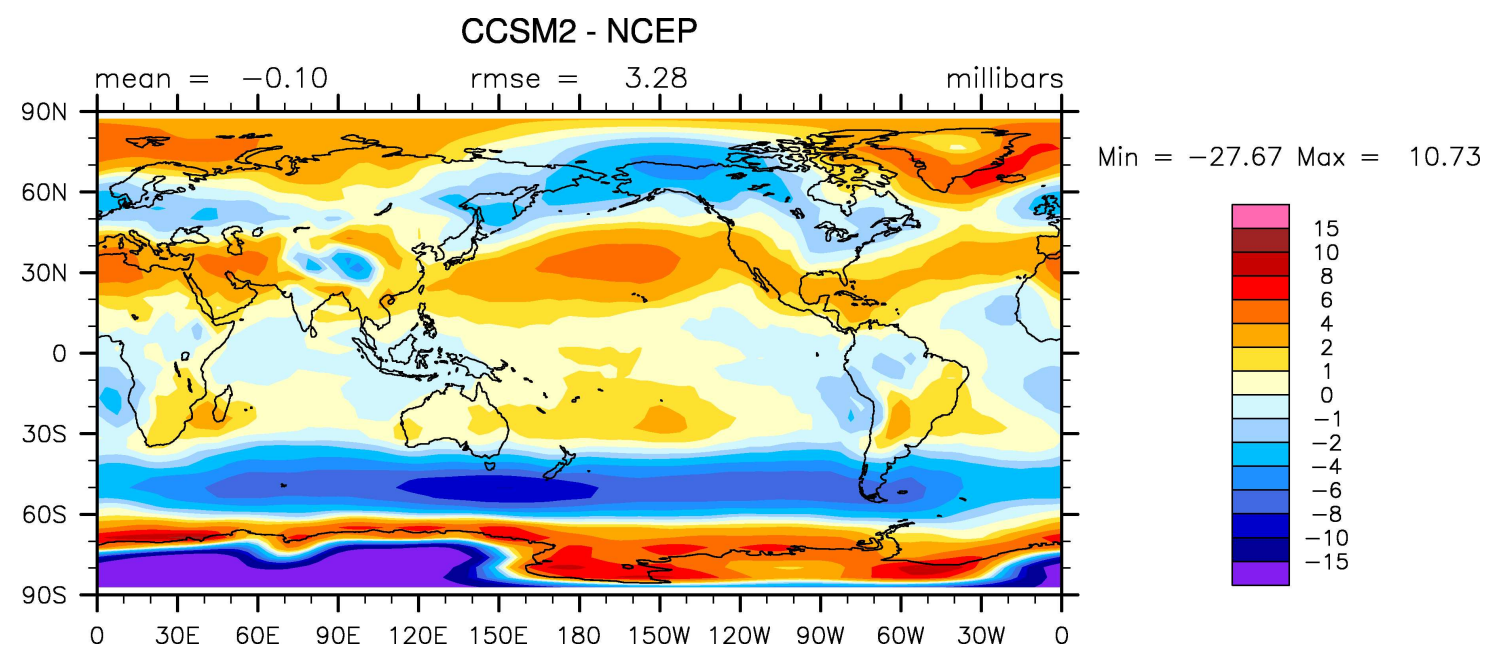

Fig. 18. Difference in annual-mean sea-level pressure between CCSM2/T31x3a and NCEP 1979-1998 reanalysis data $(\mathrm{rmse}=$ root-meansquare error).

\subsection{Climate variability}

\subsubsection{Tropical Pacific}

Tropical climate variability on the short-range timescale from a few months to several years is dominated by the El Niño/Southern Oscillation (ENSO). Figure 24 shows the wavelet power spectrum of the Niño-3.4 index (SST $5^{\circ} \mathrm{S}-$ $5^{\circ} \mathrm{N}, 170^{\circ} \mathrm{W}-120^{\circ} \mathrm{W}$ ) calculated from the synchronous integration phase of the CCSM2/T31x3a control run. The global wavelet power spectrum exhibits a maximum around 2 years, while the ENSO period deduced from observational data has a broader spectral peak near 3-7 years.

For a closer inspection of tropical Pacific variability, Fig. 25 displays Hovmöller plots of equatorial SST and 850hPa zonal-wind anomalies. A 20-year interval has been chosen which includes two very strong El Niño events (years $366 / 367$ and 368/369) and a phase of reduced ENSO frequency (years 370-378). Comparing the SST anomalies with the $850-\mathrm{hPa}$ zonal-wind anomalies reveals a strong atmosphere-ocean coupling in the model tropics. Wind anomalies are particularly pronounced during the two strong El Niño events as well as during the two strong cold La Niña events in years 365/366 and 370. Compared to observations, the amplitude of SST variations is too small in the model tropical Pacific. Moreover, CCSM2/T31x3a simulates the strongest SST fluctuations in the central part of the basin, while SST variability in the eastern Pacific is substantially underestimated. Likewise, maximum zonal-wind anomalies are situated too far in the west compared to observations.

It has been shown by Latif et al. (2001) and AchutaRao and Sperber (2002) that many climate models are not capable of simulating ENSO's phase locking to the annual cycle. To test the skill of CCSM2/T31x3a in simulating the seasonal cycle phase-locking, the interannual standard deviations of the Niño-3.4 SST anomalies are calculated as a function of calendar month (Fig. 26). Although CCSM2/T31x3a simulates a secondary maximum in August, the strongest variability occurs during boreal winter. It is therefore concluded that, compared to other models, CCSM2/T31x3a shows reasonably good skill in simulating the seasonal cycle phaselocking.

\subsubsection{North Atlantic}

Climate variability in the North Atlantic and European realm is strongly linked to the North Atlantic Oscillation (NAO), the most prominent mode of variability in Northern Hemisphere winter climate. Here, the leading large-scale pattern associated with the NAO is extracted by principal component analysis on the winter 500-hPa geopotential height field, considering a limited spatial domain $\left(90^{\circ} \mathrm{W}-30^{\circ} \mathrm{E}, 20^{\circ} \mathrm{N}-\right.$ $80^{\circ} \mathrm{N}$ ). Figure 27 shows the leading empirical orthogonal function $(\mathrm{EOF})$ obtained from the synchronous integration phase of the CCSM2/T31x3a control run. The first EOF accounts for $58.5 \%$ of the total $500-\mathrm{hPa}$ geopotential height variance over the spatial domain. This number is somewhat higher than the value calculated from NCEP reanalysis data (49.4\%). The 500-hPa height pattern consists of two centersof-action. The northern center-of-action is captured well by the model. The southern center is less well simulated, being displaced too far west and too far south over the Atlantic Ocean. 

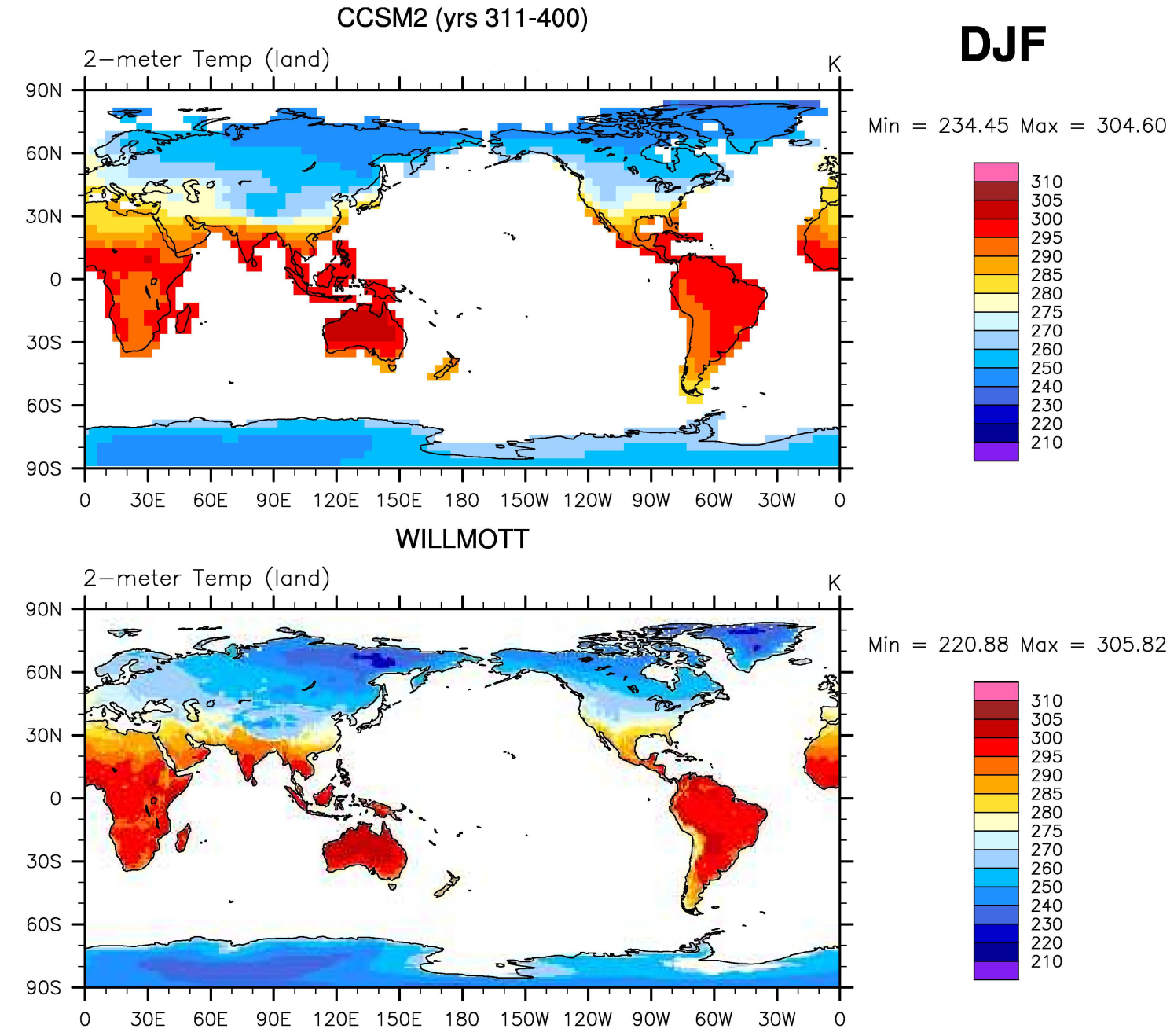

CCSM2 - WILLMOTT

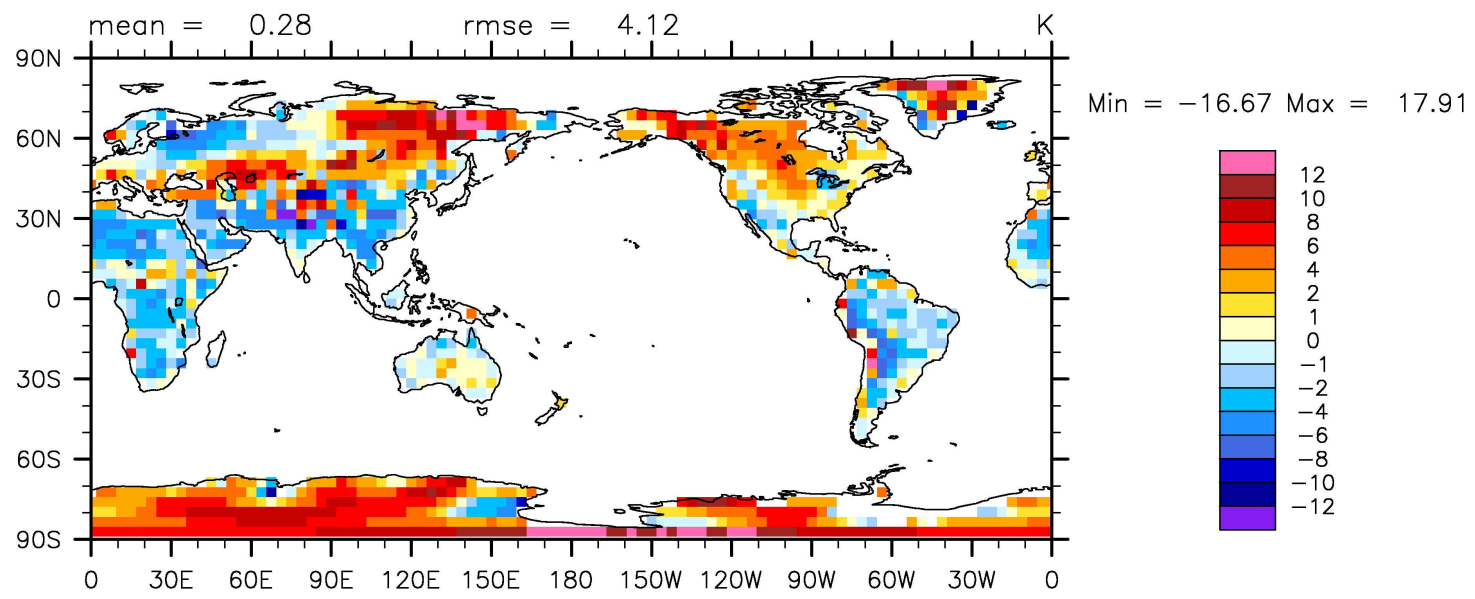

Fig. 19. December-February (DJF) reference height $(2 \mathrm{~m})$ air temperature: CCSM2/T31x3a control run versus Willmott/Matsuura 19501999 observations (rmse $=$ root-mean-square error). 
CCSM2 (yrs 311-400)
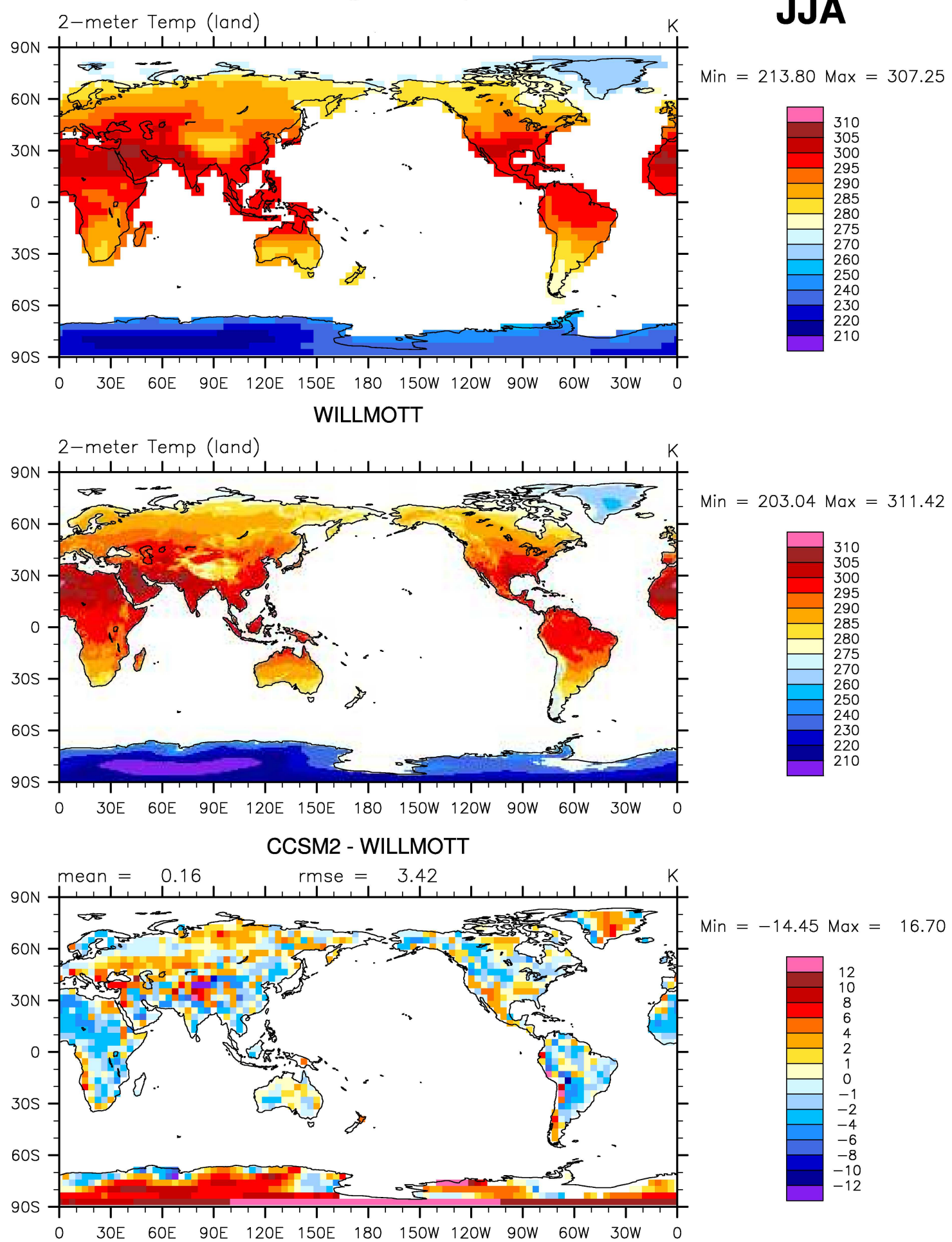

Fig. 20. June-August (JJA) reference height ( $2 \mathrm{~m}$ ) air temperature: CCSM2/T31x3a control run versus Willmott/Matsuura 1950-1999 observations $($ rmse $=$ root-mean-square error). 

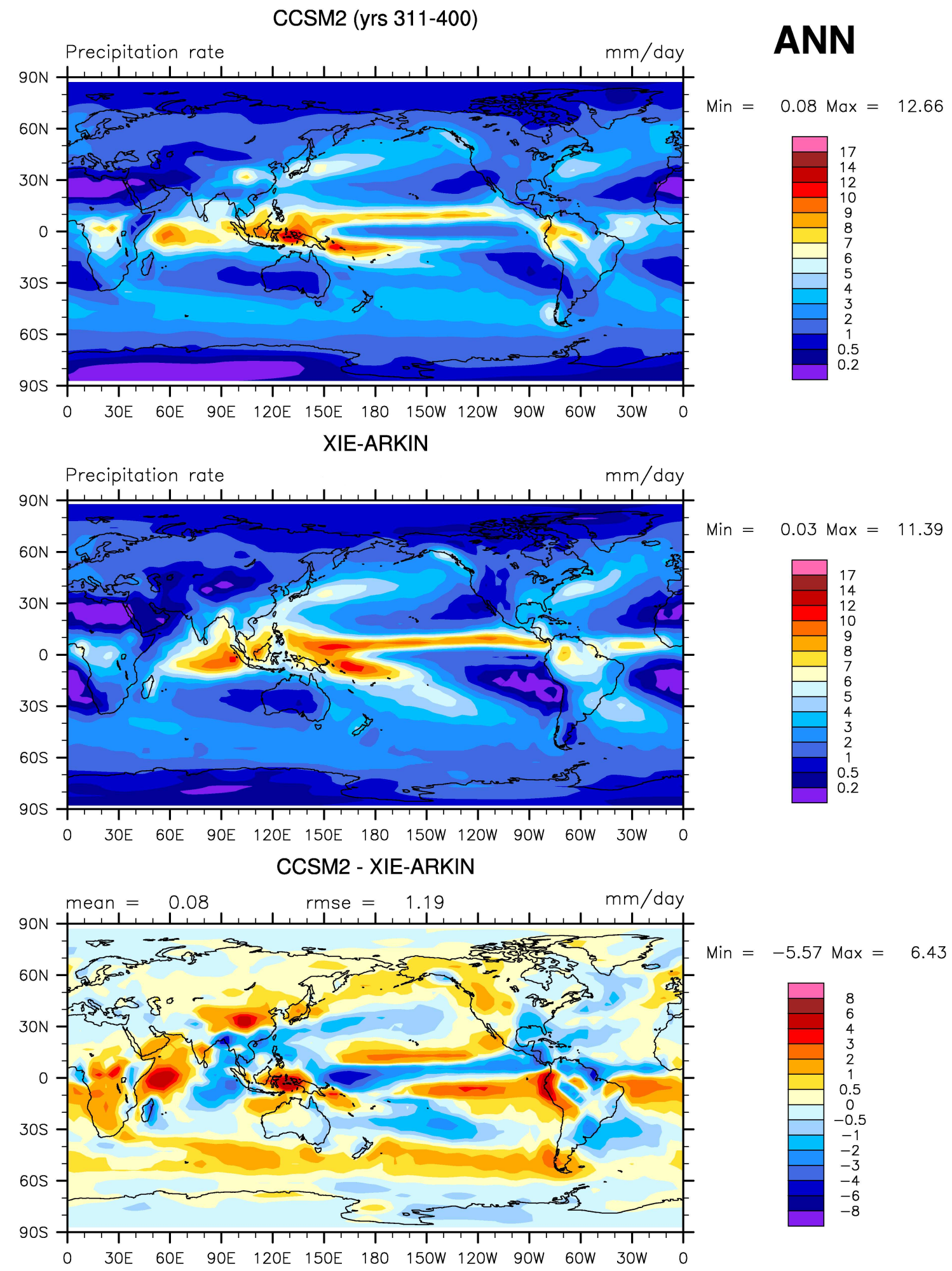

Fig. 21. Annual-mean precipitation rate: CCSM2/T31x3a control run versus Xie/Arkin (CMAP) 1979-1998 observations (rmse = rootmean-square error). 

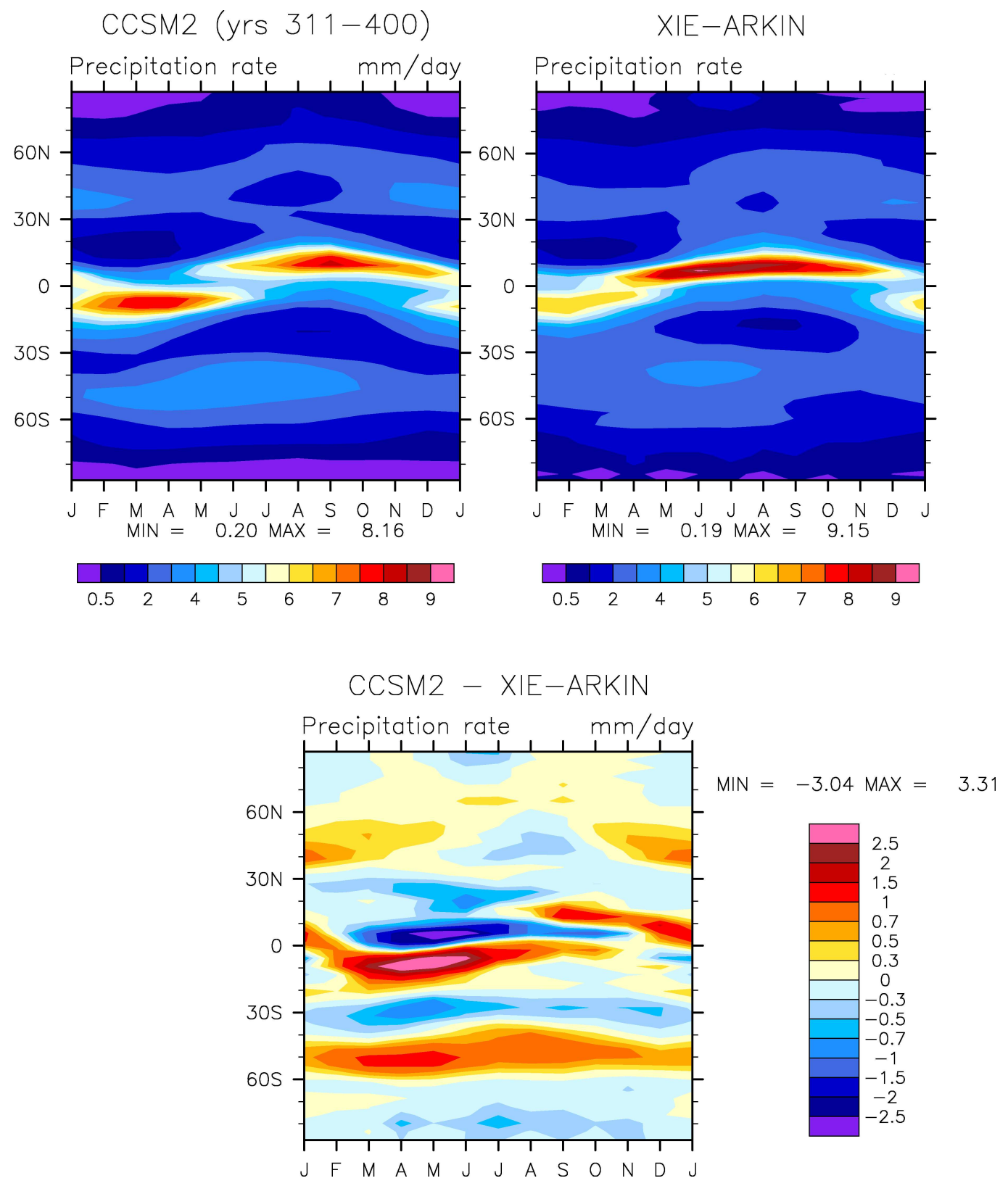

Fig. 22. Mean annual cycle of zonally averaged precipitation: CCSM2/T31x3a control run versus Xie/Arkin (CMAP) 1979-1998 observations.

\section{Discussion}

\subsection{Common biases}

CCSM2/T31x3a produces an overall reasonable present-day global climate. Nevertheless, the evaluation of the control run has revealed several shortcomings. Most of these shortcomings are well known as "typical problems" (i.e. common biases) in global, non-flux-corrected climate models. A strong surface cold bias in the equatorial Pacific, a wrong sign of the tropical Atlantic zonal SST gradient, and positive SST biases at the eastern boundaries of the subtropical Pacific and Atlantic ocean basins (coastal upwelling regions of North/South America, northwestern/southwestern Africa) were to be expected from the history of ocean climate modelling (Mechoso et al., 1995; Latif et al., 2001; AchutaRao and Sperber, 2002; Davey et al., 2002; Wittenberg et al., 2006).

Sensitivity experiments suggest that errors in both surface solar radiation (through an under-prediction of stratus 

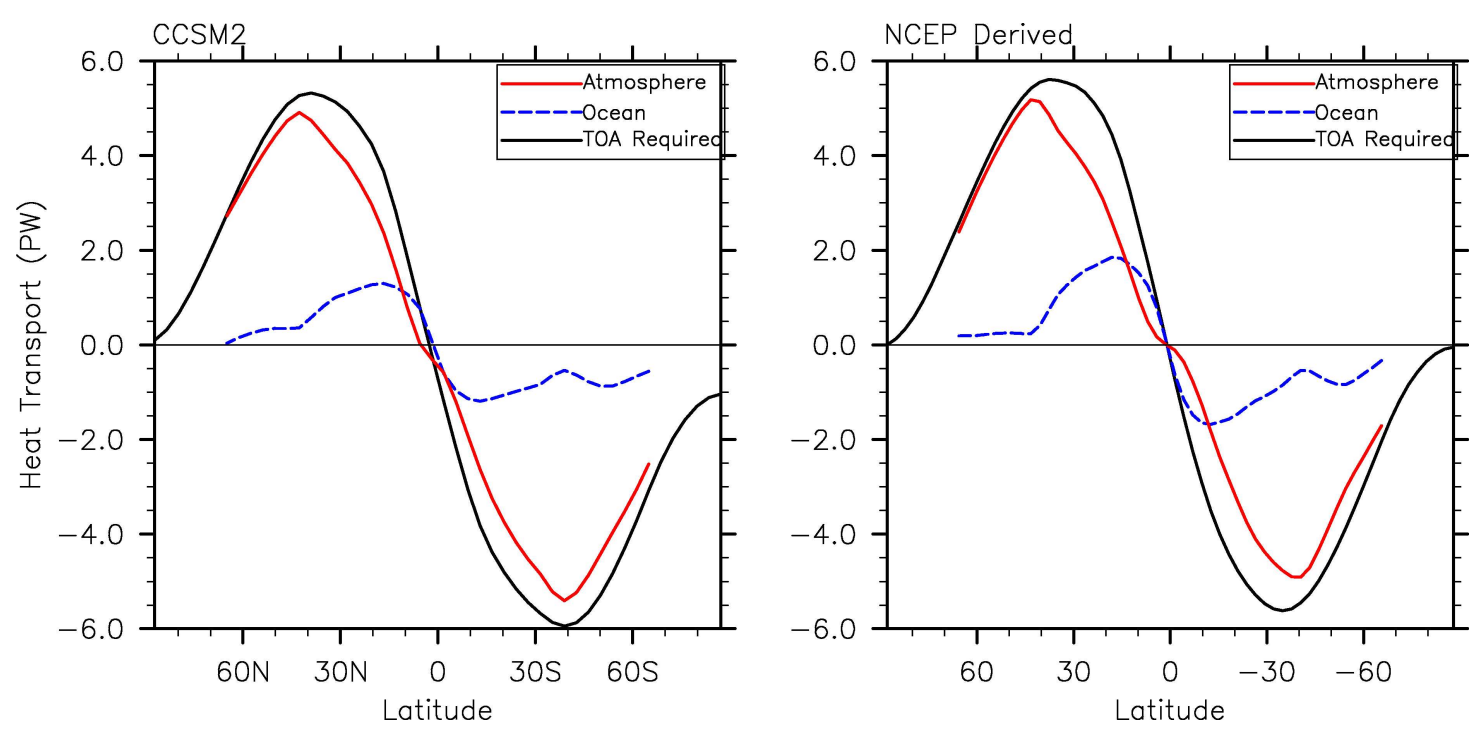

Fig. 23. Mean northward heat transports as derived from the CCSM2/T31x3a control run (left) and NCEP 1979-1998 reanalysis data (right) for ocean, atmosphere, and the coupled system (TOA = Top of atmosphere). The heat transports are total and thus include all eddy transports.
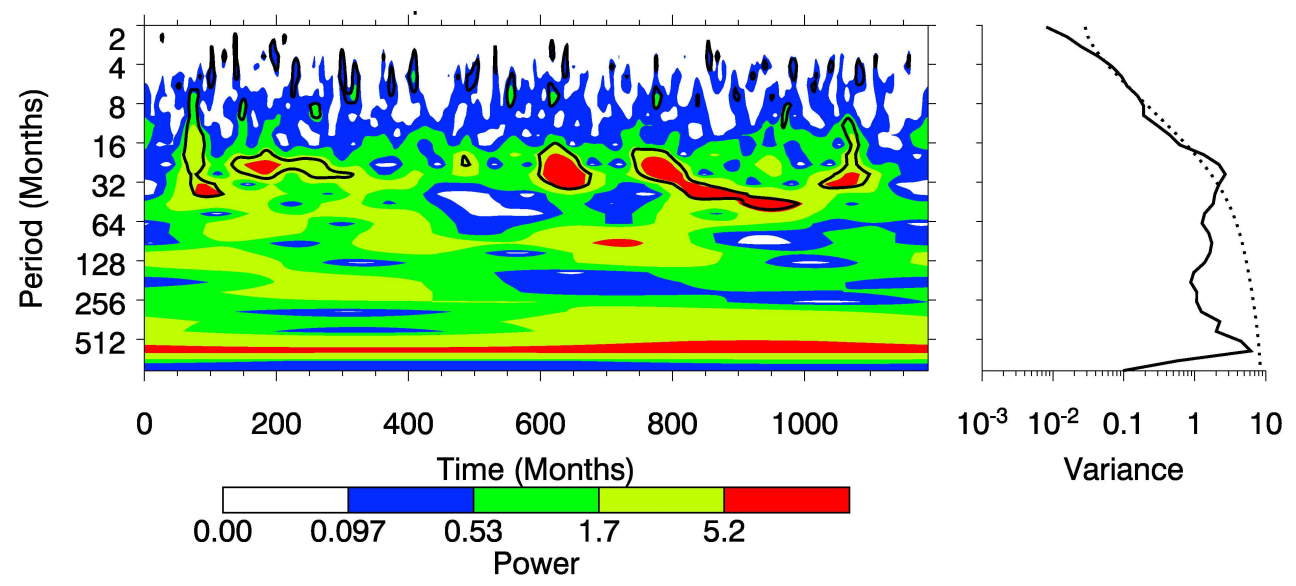

Fig. 24. Wavelet (Morlet) power spectrum (Torrence and Compo, 1998) of the Niño-3.4 index calculated from the CCSM2/T31x3a control run (monthly values from the 100-yr synchronous integration phase): Temporal evolution (left), where the contour levels are chosen so that $75 \%, 50 \%, 25 \%$, and $5 \%$ of the wavelet power $\left(\mathrm{K}^{2}\right)$ is above each level (black contour is the 5\% significance level, using a red-noise, autoregressive lag 1 background spectrum), and global wavelet power spectrum (right). The dotted curve marks the significance for the global wavelet spectrum.

clouds in the atmosphere model) and wind stress ocean forcing (driving the coastal upwelling of cold thermocline water through surface Ekman divergence) each contribute about one-half to the common eastern boundary SST bias in global climate models (Kiehl and Gent, 2004; Large and Danabasoglu, 2006). The representation of narrow coastal upwelling is also strongly dependent on the spatial resolution of the oceanic model grid. However, increasing the resolution of the ocean model does not necessarily reduce the SST bi- ases in coastal upwelling regions (Yeager et al., 2006), unless oceanic mesoscale features are properly resolved (Seo et al., 2006). It is important to note that eastern boundary surface biases are probably not confined locally. They can rather be advected over large distances and, hence, may exert largescale, remote influences over the coupled solution, even contributing to the double ITCZ problem (Li et al., 2004; Kiehl and Gent, 2004; Large and Danabasoglu, 2006). 

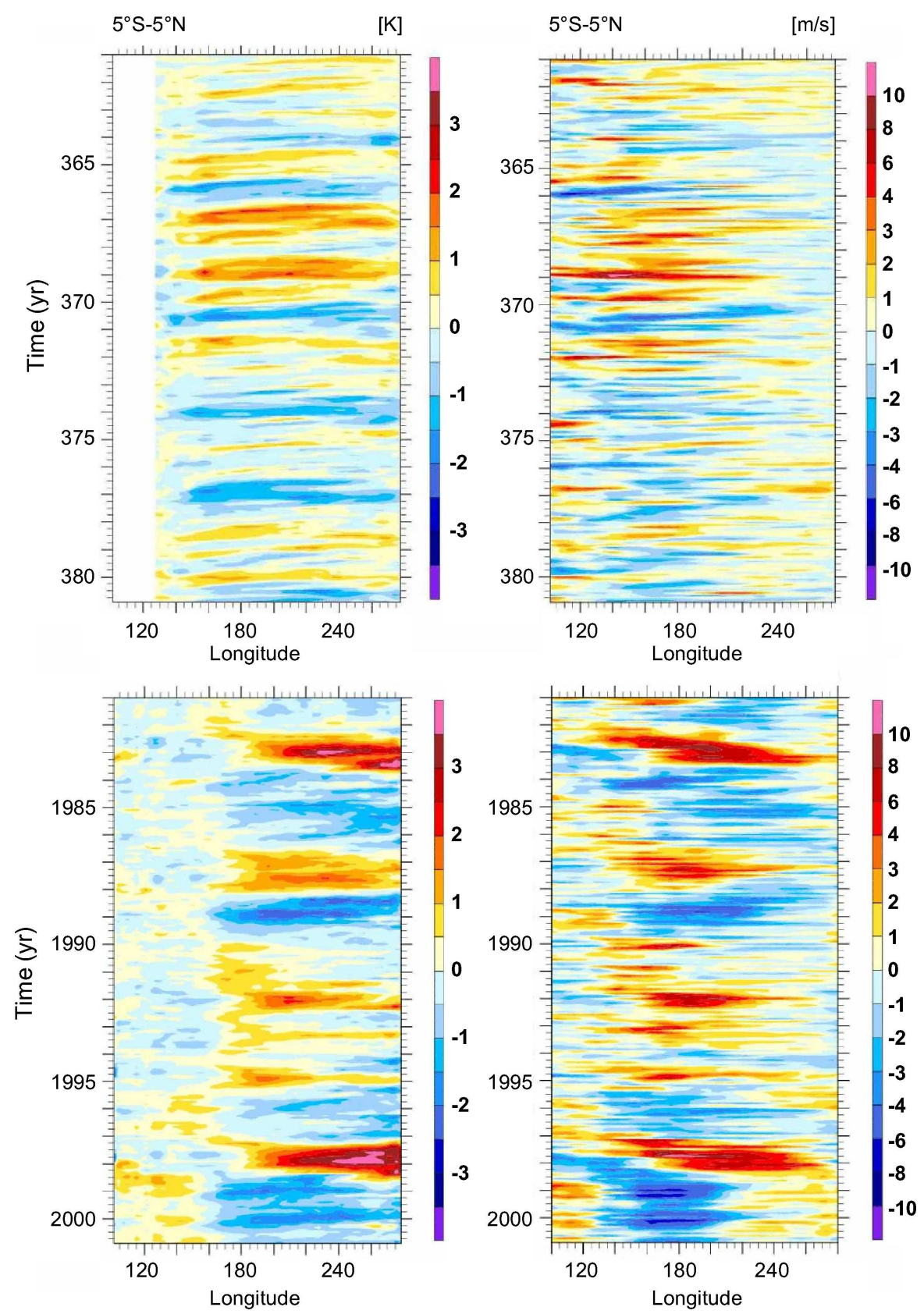

Fig. 25. Equatorial Pacific $\left(5^{\circ} \mathrm{S}-5^{\circ} \mathrm{N}\right)$ monthly anomaly Hovmöller plots for SST (left) and 850 -hPa zonal wind (right). A 20 -yr interval from the synchronous CCSM2/T31x3a integration phase is shown (top) along with NCEP 1981-2000 data (bottom).

The rainfall double ITCZ is a common problem in coupled non-flux-corrected climate models (Mechoso et al., 1995; Lambert and Boer, 2001; Harvey, 2003; Covey et al., 2003; Li et al., 2004; Dai, 2006). A better simulation of the surface hydrography in the east Pacific coastal upwelling regions might improve the spatial structure of tropical rainfall. Recently, Zhang and Wang (2006) demonstrated that the use of a modified Zhang-McFarlane convection scheme sig- nificantly mitigates the double ITCZ problem in CCSM3.0, also resulting in an improvement of the Pacific SST simulation. The annual-mean dry/wet bias over eastern/western equatorial Indian Ocean and a Northern Hemisphere midlatitude wet bias in winter are other typical precipitation errors present in many coupled models (Lambert and Boer, 2001; Covey et al., 2003). Likewise, annual warm biases over Antarctica and Greenland as well as winter (DJF) warm 


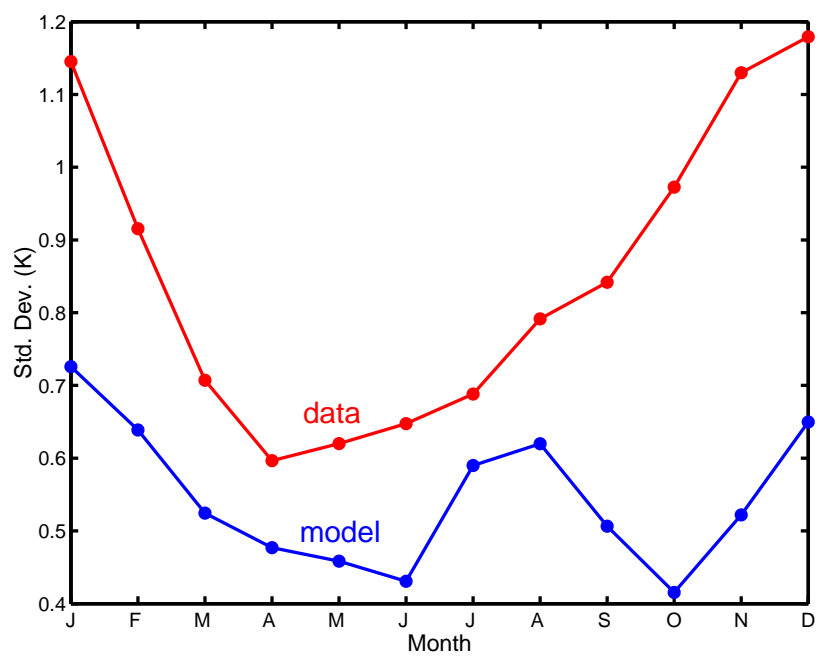

Fig. 26. Monthly standard deviations of the Niño-3.4 SST index calculated from the 100-yr synchronous CCSM2/T31x3a integration phase (blue) and from 1950-2004 NCEP data (red).

biases over northeastern Asia and northern North America are often found in climate models (Lambert and Boer, 2001; Covey et al., 2003).

The movement and distribution of sea ice is strongly determined by the high-latitude wind field. Excessive ice buildup along the Siberian coast is mainly attributable to an erroneous Arctic wind field and has been identified to be another common problem in many climate models (Bitz et al., 2002; DeWeaver and Bitz, 2006). Chapman and Walsh (2007) showed that, in the Barents Sea, nearly all state-of-the-art global climate models reveal a substantial oversimulation of sea ice associated with a strong cold bias in surface air temperature. Moreover, Chapman and Walsh (2007) pointed out that most models produce a positive SLP bias in the Eurasian sector of the Arctic Ocean.

The skill of models to simulate interannual variability in the tropical Pacific has been analysed in various studies. It has been found that most global climate models tend to produce ENSO-like variability that occurs at a higher-thanobserved frequency (periodicity of 2-3 years instead of 3-7 years), and that most models are placing the maximum SST variability in the equatorial Pacific too far to the west (Latif et al., 2001; Davey et al., 2002; AchutaRao and Sperber, 2002). Although the latest climate models tend to be more realistic in representing the frequency with which ENSO occurs, and they are better at locating enhanced SST variability over the eastern Pacific (van Oldenborgh et al., 2005; AchutaRao and Sperber, 2006), CCSM2/T31x3a's skill to simulate interannual variability in the tropical Pacific is well within the range of other models.

None of the above mentioned problems disappears in the higher-resolution (T42) version of CCSM2.0.1 or in
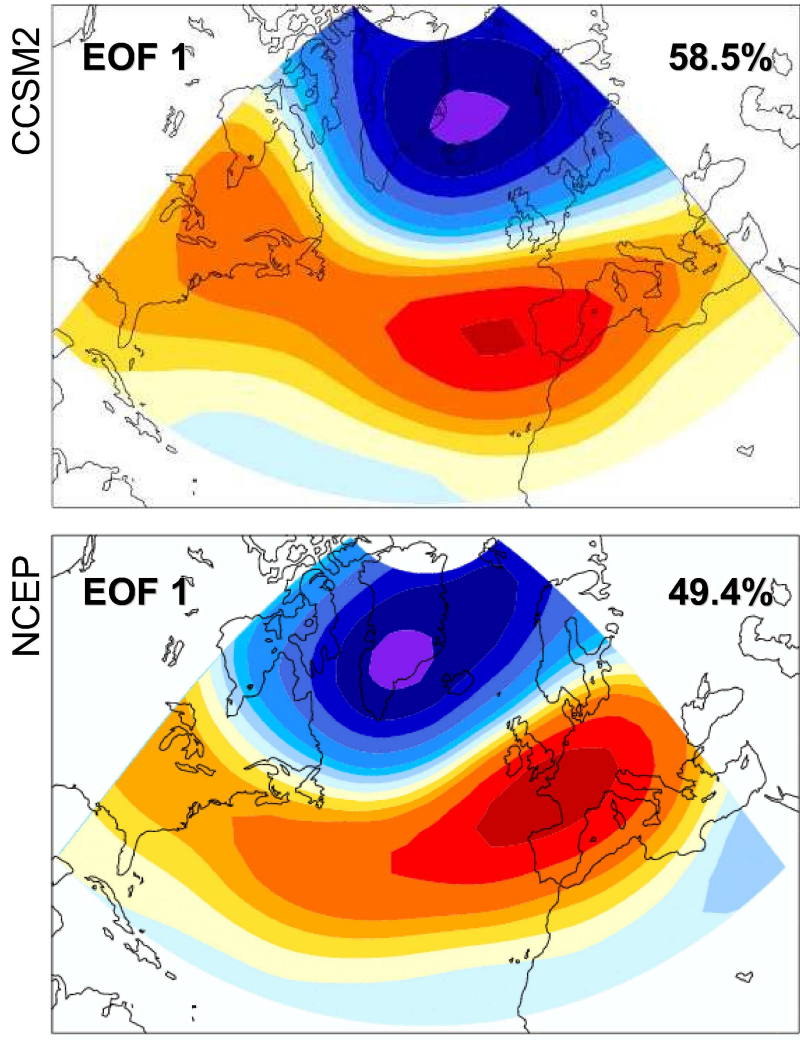

meters

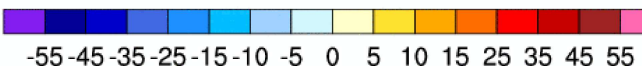

Fig. 27. Standard deviation of monthly mean 500-hPa geopotential height associated with the leading EOF corresponding to the NAO-like pattern in the North Atlantic region during four winter months (December-March) and percent variance explained: CCSM2/T31x3a synchronous integration phase (top) and NCEP reanalysis data (bottom).

the latest model release, CCSM3.0. Basically, control runs of CCSM2/T42, CCSM3/T31, CCSM3/T42 (and even CCSM3/T85) still suffer from the same shortcomings with respect to precipitation, sea/land surface temperatures, seaice distribution (in both hemispheres) and tropical climate variability (see Kiehl and Gent, 2004; Yeager et al., 2006; Holland et al., 2006; Deser et al., 2006; DeWeaver and Bitz, 2006). Even though the winter surface warm bias over northeastern Asia and northern North America is reduced in CCSM3/T31 compared to CCSM2/T31x3a, the errors are similar in the higher resolution versions CCSM3/T42 and CCSM3/T85 (see www.ccsm.ucar.edu/experiments). Table 3 summarizes errors of some globally averaged climatological quantities for different versions of the Community Climate System Model. Different climate variables are simulated with different levels of success by the different models and no one model is best for all variables. 

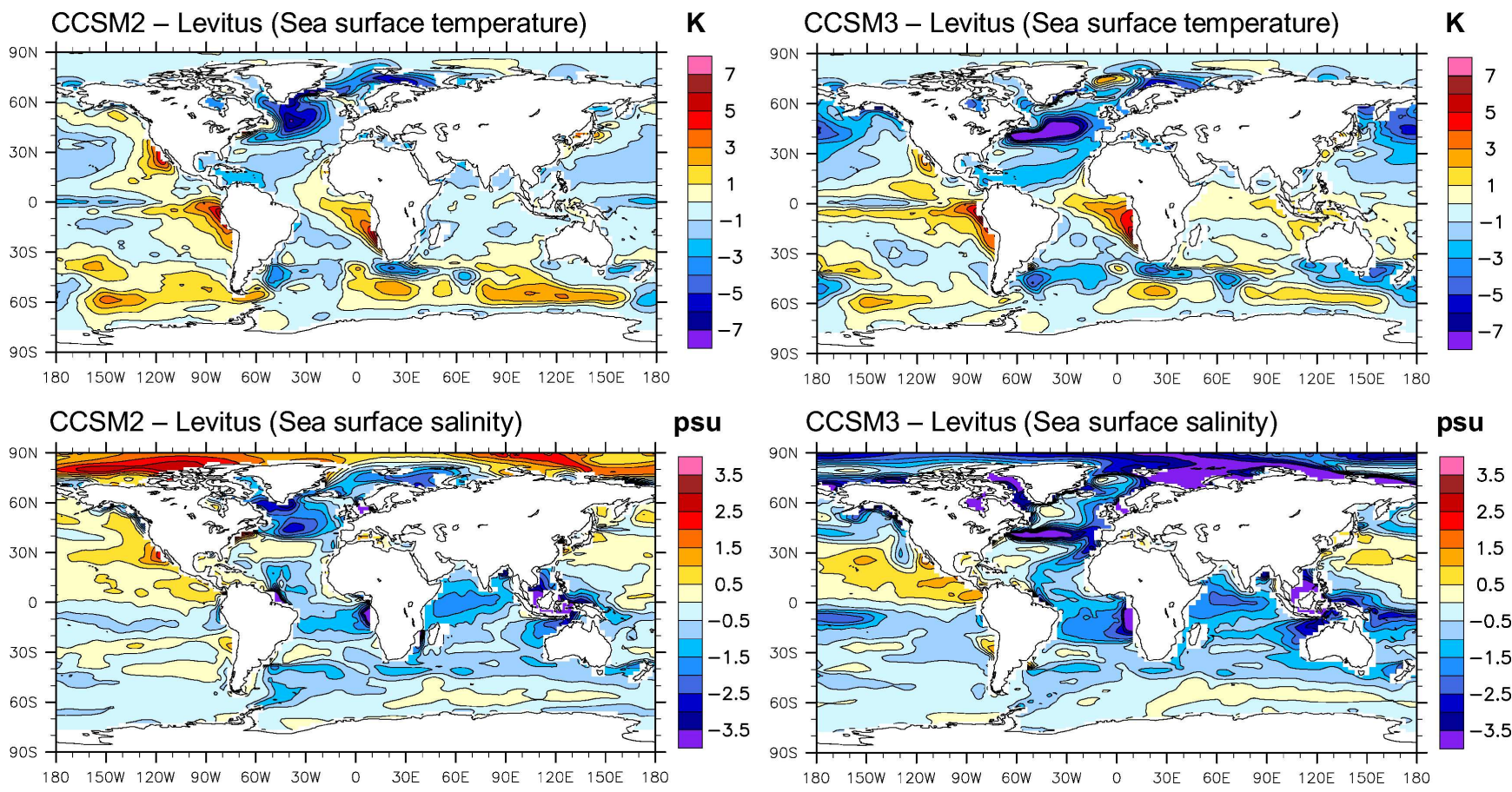

psu

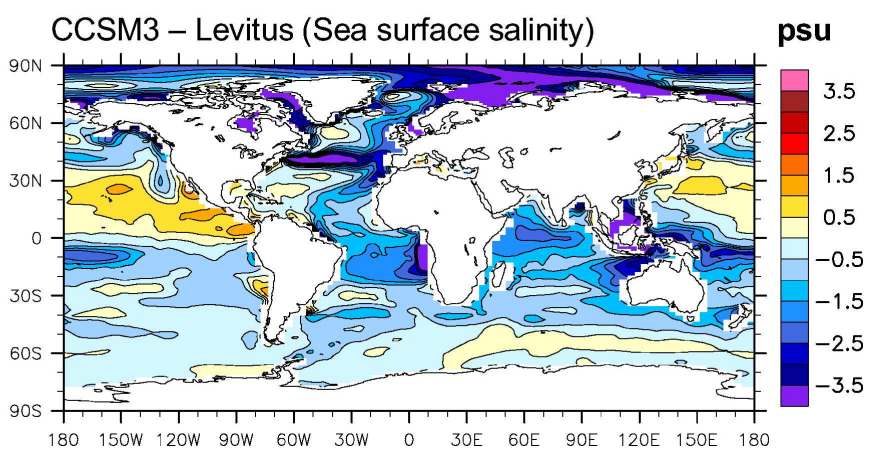

Fig. 28. Annual-mean SST (top) and surface salinity (bottom) differences between CCSM control runs (CCSM2/T31x3a, left; CCSM3/T31, right) and observations.

Table 3. Errors of mean values (first number) and root-mean-square errors (second number) with respect to global climatologies for different versions of the Community Climate System Model (T31: low resolution; T42: medium resolution; T2m: 2-meter air temperature over land). The values for CCSM2/T42, CCSM3/T31 and CCSM3/T42 were taken from www.ccsm.ucar.edu/experiments and refer to the 1990 AD control runs b20.007 (average over years 561-580), b30.031 (average over years 801-820), and b30.004 (average over years 801-820), respectively.

\begin{tabular}{lccccc}
\hline Data set & $\begin{array}{c}\text { CCSM2/ } \\
\text { T31x3a }\end{array}$ & $\begin{array}{c}\text { CCSM2/ } \\
\text { T42 }\end{array}$ & $\begin{array}{c}\text { CCSM3/ } \\
\text { T31 }\end{array}$ & $\begin{array}{c}\text { CCSM3/ } \\
\text { T42 }\end{array}$ & Units \\
& & & & & \\
\hline NCEP SLP (DJF) & $+0.34,3.84$ & $+0.21,3.62$ & $-0.21,3.91$ & $-0.30,3.17$ & $\mathrm{hPa}$ \\
NCEP SLP (JJA) & $-0.38,4.97$ & $-0.47,5.72$ & $-0.97,5.69$ & $-1.00,6.67$ & $\mathrm{hPa}$ \\
Willmott T2m (DJF) & $+0.28,4.12$ & $+1.57,4.70$ & $-0.24,3.70$ & $+1.02,3.93$ & $\mathrm{~K}$ \\
Willmott T2m (JJA) & $+0.16,3.42$ & $+1.11,3.36$ & $-1.04,3.69$ & $-0.26,3.32$ & $\mathrm{~K}$ \\
CMAP Prec. (Ann.) & $+0.08,1.19$ & $+0.16,1.24$ & $+0.03,1.28$ & $+0.10,1.38$ & $\mathrm{~mm} / \mathrm{day}$ \\
\hline
\end{tabular}

\subsection{Potential side-effects of AMOC tuning}

The tuning applied to CCSM2/T31x3a primarily aims at amplifying the AMOC. However, parameter changes might have substantial negative side-effects. In particular, Meehl et al. (2001) showed that larger values of vertical diffusivity may reduce ENSO variance due to a lower sharpness of the tropical thermocline. Based on the results of uncoupled ocean-only sensitivity experiments, it has also been suggested that the ACC volume transport through Drake Passage decreases with increasing horizontal or isopycnal diffusivities (Danabasoglu and McWilliams, 1995).

Indeed, CCSM2/T31x3a has a relatively anemic ENSO and the volume transport through Drake Passage is significantly smaller than observation-based estimates (see above). In order to assess the influence of enhanced mixing coefficients on ENSO and the ACC in CCSM2/T31x3a it is instructive to look at these metrics in the standard CCSM2/T31 control run. This control run was initialized with observational data and has been integrated (synchronously) for 287 
CCSM2 - Levitus

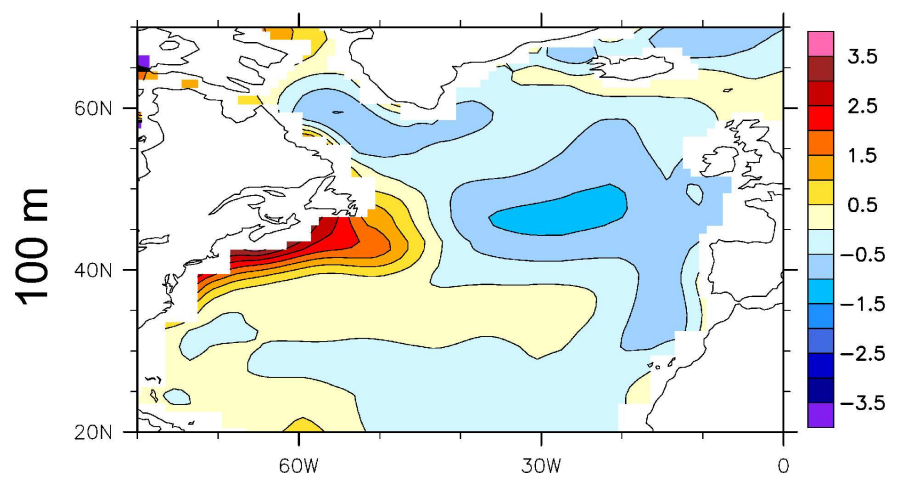

CCSM3 - Levitus

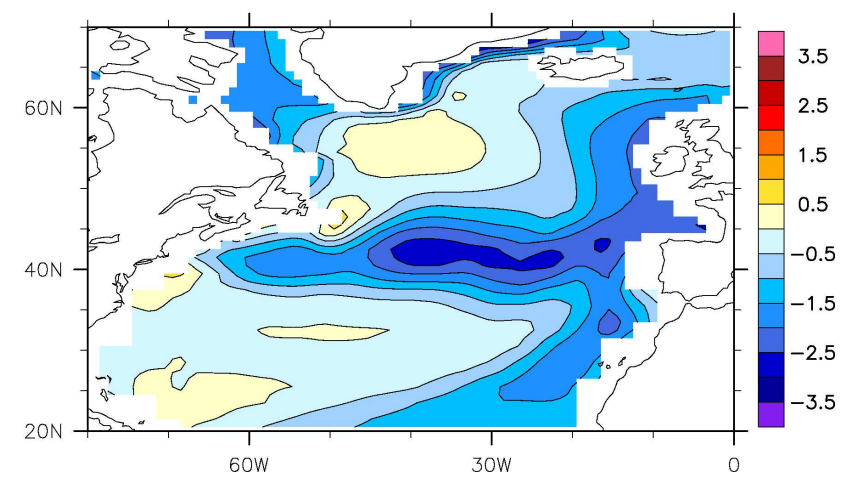

Fig. 29. Annual-mean salinity differences (psu) between CCSM control runs (CCSM2/T31x3a, left; CCSM3/T31, right) and observations at $100 \mathrm{~m}$ depth in the North Atlantic.

years. Although the deep ocean has not reached equilibrium after this relatively short integration time, one can expect that both the volume transport of the ACC and the hydrography of the uppermost layers in the equatorial Pacific Ocean have largely been spun up.

Despite smaller horizontal mixing coefficients in the standard CCSM2/T31 (cf. Sect. 2), the 10-year (years 278-287 of the control run) averaged ACC transport through Drake Passage is only $80.3 \mathrm{~Sv}$, i.e. more than $10 \mathrm{~Sv}$ smaller than in CCSM3/T31x3a. Obviously, other (unknown) effects overcompensate for the influence of horizontal mixing on the ACC transport in the complex coupled system. Likewise, the effect of enhanced vertical mixing in CCSM2/T31 x3a on ENSO variability is elusive. The standard deviation of annual mean Niño-3.4 SST in the CCSM2/T31x3a control run is $0.36^{\circ} \mathrm{C}$, which is substantially smaller than the observational value (ca. $0.64^{\circ} \mathrm{C}$ for the period 1950-2005 AD). In the standard CCSM2/T31 control run, the standard deviation of annual mean Niño-3.4 SST is $0.42^{\circ} \mathrm{C}$ for the 10 -year interval 278-287. Although the ENSO variance in CCSM2/T31 is slightly larger than in CCSM2/T31x3a (which was to be expected as the background vertical mixing in the upper ocean is enhanced in CCSM2/T31x3a), this difference is not significant at the 0.05 significance level according to an F-test. In summary, the negative side-effects of enhanced vertical mixing coefficients in CCSM2/T31x3a prove to be small or even negligible with respect to ACC and ENSO dynamics.

\subsection{Comparisons with CCSM3/T31}

Even though a detailed model intercomparison is far beyond the scope of this paper, some examples shall be shown in which CCSM2/T31x3a provides a better simulation than CCSM3/T31. For this purpose, a present-day (1990 AD) control run with the standard CCSM3/T31 serves as a reference (experiment b30.031; output data downloaded from www.earthsystemgrid.org). Starting from observational data, CCSM3/T31 was synchronously integrated for 879 years. For the following comparisons with CCSM2/T31x3a, 80year averages (years 800-879) from the CCSM3/T31 control run are used.

Figure 28 shows the global fields of SST and surface salinity errors from the CCSM2/T31x3a and CCSM3/T31 control runs. Both models are unable to produce the cold temperatures observed in coastal upwelling regions. In CCSM3/T31, a cold bias is particularly pronounced $\left(>7^{\circ} \mathrm{C}\right)$ in the North Pacific and North Atlantic oceans, where the SSTs in CCSM2/T31 33 a are much closer to observations. As to surface salinity biases in CCSM3/T31 and CCSM2/T31x3a, the errors are quite comparable. The most obvious differences are visible at high northern latitudes. In the northern North Pacific, CCSM2/T31x3a overestimates surface salinity, while CCSM3/T31 is too fresh. CCSM2/T31x3a's surface salinities are also too high in the Arctic Ocean, where CCSM3/T31 tends to produce extremely fresh water masses. Both models simulate too fresh water in the northern North Atlantic. A zonal low-salinity tongue at around $40^{\circ} \mathrm{N}$, however, is particularly troublesome in CCSM3/T31. This fresh bias is not restricted to the surface; it spoils the simulation also at subsurface levels (Fig. 29).

SST errors can have a direct effect on atmospheric circulation and precipitation patterns. For instance, it is well known that the strength of the West African monsoon is largely controlled by the large-scale SST distribution (e.g. Lamb, 1978; Folland et al., 1986; Giannini et al., 2003). One can therefore expect that the SST biases found in the CCSM2/T31x3a and CCSM3/T31 control runs (Fig. 28) affect the simulation skills of African rainfall. Observed mean summer (JulySeptember) precipitation and reanalyzed near-surface winds over West Africa are displayed in Fig. 30 along with the simulated fields from the CCSM2/T31x3a and CCSM3/T31 control runs. The reanalyzed northward low-level monsoon 

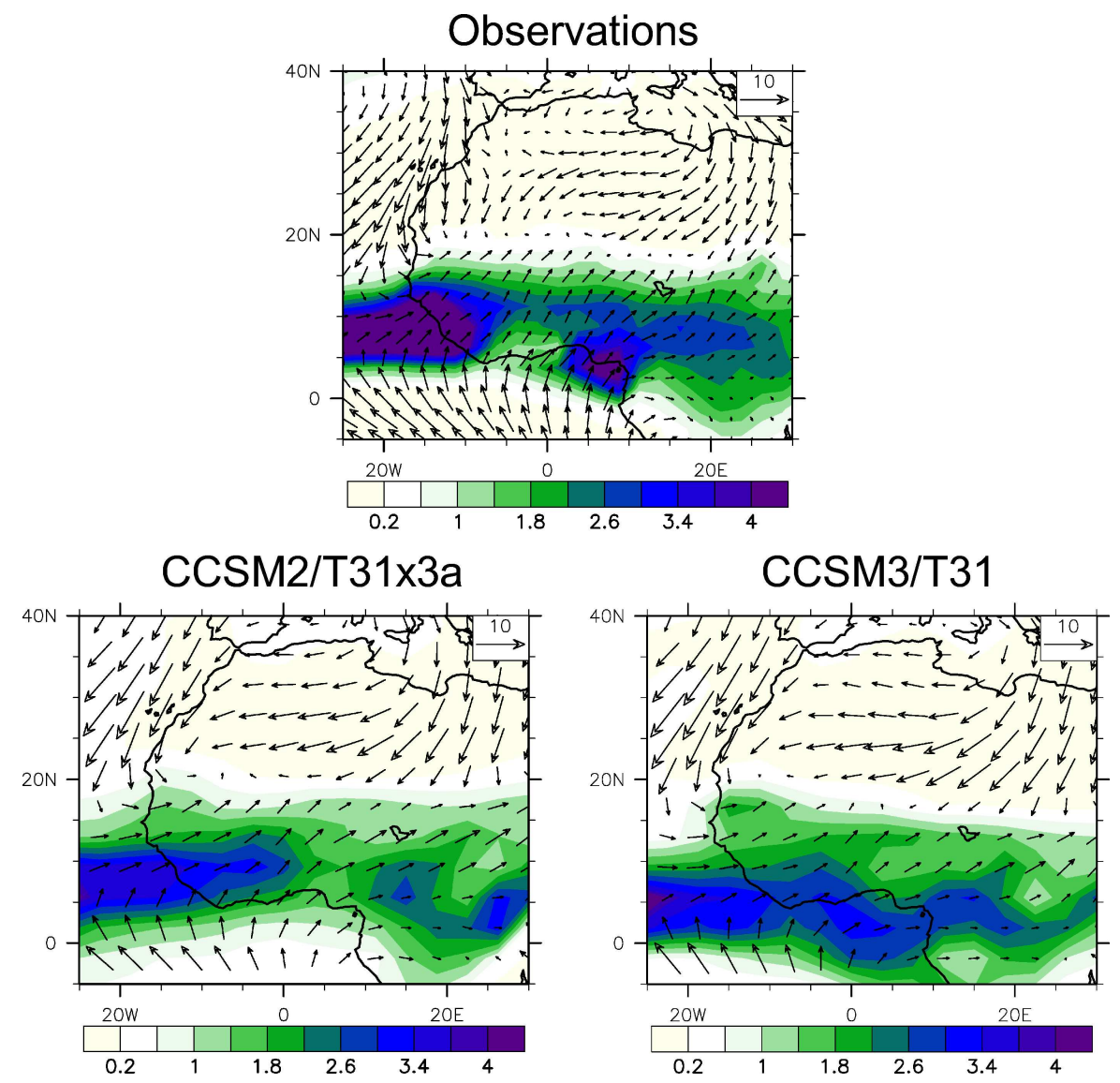

Fig. 30. Mean precipitation $(\mathrm{m} / \mathrm{yr})$ and near-surface winds $(\mathrm{m} / \mathrm{s})$ over West Africa for July-September as calculated from observational/NCEP reanalysis data (top) and CCSM control runs (bottom). The land data for the precipitation climatology are based on historical rain gauge measurements (Legates and Willmott, 1990), while oceanic precipitation is estimated from the Microwave Sounding Unit (Spencer, 1993).

flow penetrates as far north as $20^{\circ} \mathrm{N}$, where it converges with dry northerly winds at the monsoon trough. Both the wind and precipitation patterns are rather well captured by CCSM2/T31x3a. Most importantly, summer precipitation maxima reside on the African continent. By contrast, CCSM3/T31's simulation of the summer low-level wind and precipitation fields over North Africa reveals several critical shortcomings. The northerly winds penetrate too far south, while the southerly monsoon flow is too weak (cf. Fig. 31). The most crucial problem in the CCSM3/T31 control run is the location of the tropical precipitation band. The model does not adequately simulate the summer migration of the rain belt onto the African continent. Instead, tropical precipitation maxima reside over the Guinea coast and over the Gulf of Guinea. It has been hypothesized that simulated warmerthan-observed SSTs in the Gulf of Guinea are responsible for excessive rainfall south of the Guinea coast (Meehl et al., 2006). The comparison between CCSM2/T31x3a and CCSM3/T31 corroborates this hypothesis, since the Gulf of
Guinea warm bias is much more pronounced in CCSM3/T31 than in CCSM2/T31x3a (cf. Fig. 28).

\section{Conclusions}

The low-resolution version ("paleo version") of CCSM2.0.1 has been revisited. The original release has been adjusted by deepening the Greenland-Scotland ridge, changing oceanic mixing parameters, and applying a regional freshwater flux adjustment at high northern latitudes. The overall goal of these model adjustments, i.e. the improvement of the AMOC, has been achieved. Even though the flow of NADW is relatively shallow and the total formation of $\mathrm{AABW}$ is weaker than observation-based estimates suggest, CCSM2/T31x3a appears to be a suitable tool for (paleoclimatic) studies concerning the role of AMOC variations in global climate change. It is worth noting that CCSM2/T31x3a does not rely on wind-stress correction to produce ENSO variability, unlike other coarse-resolution coupled climate models (e.g. 


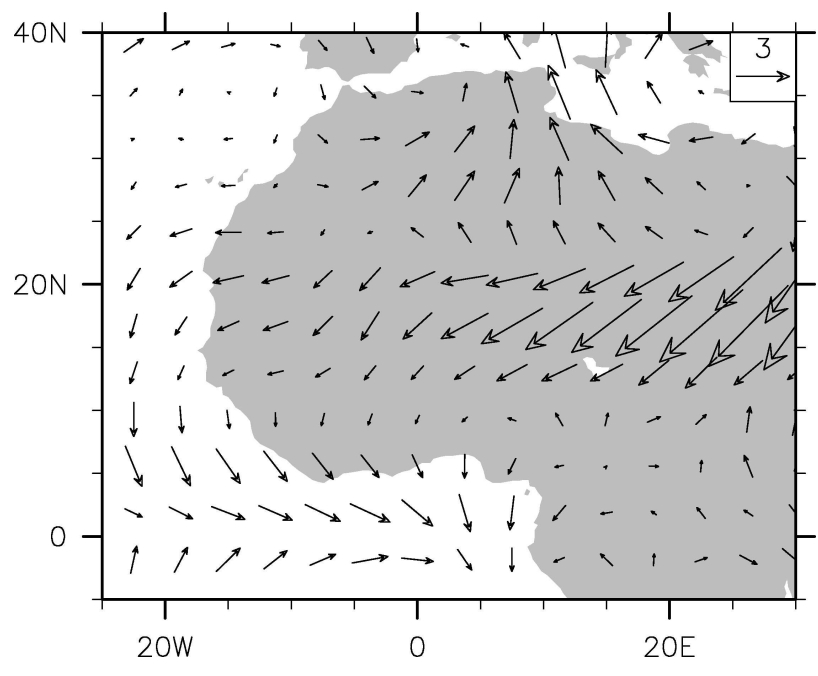

Fig. 31. Difference in July-September near-surface winds $(\mathrm{m} / \mathrm{s})$ between CCSM3/T31 and CCSM2/T31x3a over West Africa.

Mikolajewicz et al., 2007). Heat flux adjustment is not implemented either. The absence of air-sea heat flux adjustment avoids distortion in the non-linear dependence of heat fluxes on SST and sea ice.

In the present paper, important aspects of the present-day control run of CCSM2/T31x3a have been analysed, and major shortcomings have been exposed. Most biases found in the CCSM2/T31x3a control run have been identified as "typical problems" in global climate modelling. Examples have been shown in which CCSM2/T31x3a has a better simulation skill than CCSM3/T31 (North Atlantic hydrography, West African monsoon). On the other hand, CCSM3/T31 has a stronger and more realistic ENSO SST variability in the tropical Pacific (cf. Yeager et al., 2006). There is also no doubt that for applications in which variations of the Arctic Ocean freshwater budget play a crucial role, special care should be taken with CCSM2/T31x3a due to the implementation of the arctic/subarctic flux adjustment. Nevertheless, depending on the phenomenon under investigation and its geographical location, CCSM2/T31x3a is a useful alternative to CCSM3/T31. Given its good simulation skills and its relatively low resource demands, CCSM2/T31x3a shows promise for studies of paleoclimate and other applications requiring long integrations and equilibrated solutions.

Acknowledgements. The manuscript has benefited tremendously from comments and suggestions by Stephen Griffies. I would like to thank Michael Schulz and Ute Merkel for stimulating discussions and three anonymous reviewers as well as David Webb for their constructive comments. I am indebted to Manuel Renold and Christoph Raible for providing their POP analysis software. Thanks is due to Mark J. Stevens for making the CCSM Diagnostics Package available. The software package can be downloaded from www.cgd.ucar.edu/cms/stevens/master.html. The model run was performed on the IBM pSeries 690 Supercomputer of the "Norddeutscher Verbund für Hoch- und Höchstleistungsrechnen" (HLRN). This work was funded through the DFG Research Center/Excellence Cluster "The Ocean in the Earth System" (MARUM0579).

Edited by: D. Webb

\section{References}

AchutaRao, K. and Sperber, K. R.: Simulation of the El Niño Southern Oscillation: Results from the Coupled Model Intercomparison Project, Clim. Dynam., 19, 191-209, 2002.

AchutaRao, K. and Sperber, K. R.: ENSO simulation in coupled ocean-atmosphere models: are the current models better?, Clim. Dynam., 27, 1-15, 2006.

Alley, R. B. and Agustsdottir, A. M.: The 8k event: Cause and consequences of major Holocene abrupt climate change, Quat. Sci. Rev., 24, 1123-1149, 2005.

Bitz, C. M., Fyfe, J. C., and Flato, G. M.: Sea ice response to wind forcing from AMIP models, J. Climate, 15, 522-536, 2002.

Bitz, C. M., Holland, M., Weaver, A. J., and Eby, M.: Simulating the ice-thickness distribution in a coupled climate model, J. Geophys. Res., 106, 2441-2464, 2001.

Bitz, C. M. and Lipscomb, W. H.: An energy-conserving thermodynamic model of sea ice, J. Geophys. Res., 104, 15 669-15 677, 1999.

Bourke, R. H. and Garrett, R. P.: Sea ice thickness distribution in the Arctic Ocean, Cold Reg. Sci. Technol., 13, 259-280, 1987.

Branstetter, M. L. and Erickson, D. J.: Continental runoff dynamics in the Community Climate System Model (CCSM2) control simulation, J. Geophys. Res., 108, 4550, doi:10.1029/2003JD003212, 2003.

Briegleb, B. P., Bitz, C. M., Hunke, E. C., Lipscomb, W. H., and Schramm, J. L.: Description of the Community Climate System Model version 2: Sea ice model, Technical Report, Los Alamos National Laboratory, Los Alamos, New Mexico, National Center for Atmospheric Research, Boulder, Colorado, http://www.ccsm. ucar.edu/models/ccsm2.0.1/csim, 2002.

Broecker, W., Bond, G., Klas, M., Clark, E., and McManus, J.: Origin of the North Atlantic's Heinrich events, Clim. Dynam., 6, 265-273, 1992.

Bryan, F.: Parameter sensitivity of primitive equation ocean general circulation models, J. Phys. Oceanogr., 17, 970-986, 1987.

Bryan, K.: Accelerating the convergence to equilibrium in oceanclimate models, J. Phys. Oceanogr., 14, 666-673, 1984.

Bryan, K.: Efficient methods for finding the equilibrium climate of coupled ocean-atmosphere models, in: Physically-based modelling and simulation of climate and climate change - Part I, edited by: Schlesinger, M. E., Kluwer Academic Publishers, 567-582, 1988.

Bryan, K. and Lewis, L. J.: A water mass model of the world ocean, J. Geophys. Res., 84, 2503-2517, 1979.

Canuto, C., Hussaini, M. Y., Quarteroni, A., and Zang, T. A.: Spectral methods in fluid dynamics, Springer-Verlag, Berlin, 567 pp., 1988.

Chapman, W. J. and Walsh, J. E.: Simulations of Arctic temperature and pressure by global coupled models, J. Climate, 20, 609-632, 2007. 
Claussen, M., Mysak, L. A., Weaver, A. J., et al.: Earth system models of intermediate complexity: Closing the gap in the spectrum of climate system models, Clim. Dynam., 18, 579-586, 2002.

Collins, W. D., Hack, J. J., Boville, B. A., et al.: Description of the NCAR Community Atmosphere Model (CAM2), Technical Report, National Center for Atmospheric Research, Boulder, Colorado, http://www.ccsm.ucar.edu/models/atm-cam/docs/cam2.0/ description/index.html, 2003.

Covey, C., AchutaRao, K. M., Cubasch, U., et al.: An overview of results from the Coupled Model Intercomparison Project, Global Planet. Change, 37, 103-133, 2003.

Dai, A.: Precipitation characteristics in eighteen coupled climate models, J. Climate, 19, 4605-4630, 2006.

Danabasoglu, G.: A comparison of global ocean general circulation model solutions obtained with synchronous and accelerated integration methods, Ocean Model., 7, 323-341, 2004.

Danabasoglu, G. and McWilliams, J. C.: Sensitivity of the global ocean circulation to parameterizations of mesoscale tracer transports, J. Climate, 8, 2967-2987, 1995.

Danabasoglu, G., McWilliams, J. C., and Gent, P. R.: The role of mesoscale tracer transports in the global ocean circulation, Science, 264, 1123-1126, 1994.

Danabasoglu, G., McWilliams, J. C., and Large, W. G.: Approach to equilibrium in accelerated global oceanic models, J. Climate, 9, 1092-1110, 1996.

Davey, M. K., Huddleston, M., Sperber, K. R., et al.: STOIC: a study of coupled model climatology and variability in tropical ocean regions, Clim. Dynam., 18, 403-420, 2002.

Deser, C., Capotondi, A., Saravanan, R., and Phillips, A. S.: Tropical Pacific and Atlantic climate variability in CCSM3, J. Climate, 19, 2451-2481, 2006.

DeWeaver, E. and Bitz, C. M.: Atmospheric circulation and its effect on Arctic sea ice in CCSM3 simulations at medium and high resolution, J. Climate, 19, 2415-2436, 2006.

Driscoll, N. W. and Haug, G. H.: A short circuit in the ocean's thermohaline circulation: A cause for northern hemisphere glaciation?, Science, 282, 436-438, 1998.

Dukowicz, J. K. and Smith, R. D.: Implicit free-surface formulation of the Bryan-Cox-Semtner ocean model, J. Geophys. Res., 99, 7991-8014, 1994.

Folland, C. K., Palmer, T. N., and Parker, D. E.: Sahel rainfall and worldwide sea temperatures, Nature, 320, 602-607, 1986.

Ganachaud, A. and Wunsch, C.: Improved estimates of global ocean circulation, heat transport and mixing from hydrographic data, Nature, 408, 453-457, 2000.

Gent, P. R. and McWilliams, J. C.: Isopycnal mixing in ocean circulation models, J. Phys. Oceanogr., 20, 150-155, 1990.

Gerdes, R. and Koeberle, C.: On the influence of DSOW in a numerical model of the North-Atlantic general circulation, J. Phys. Oceanogr., 25, 2624-2642, 1995.

Giannini, A., Saravanan, R., and Chang, P.: Oceanic forcing of Sahel rainfall on interannual to interdecadal time scales, Science, 302, 1027-1030, 2003.

Gnanadesikan, A.: A simple predictive model for the structure of the oceanic pycnocline, Science, 283, 2077-2079, 1999.

Gnanadesikan, A., Dixon, K. W., Griffies, S. M., et al.: GFDL's CM2 global coupled climate models. Part II: The baseline ocean simulation, J. Climate, 19, 675-697, 2006.

Gordon, A. L.: Inter-ocean exchange of thermocline water, J. Geo- phys. Res., 91, 5037-5046, 1986.

Gordon, A. L.: Interocean exchange, in: Ocean circulation and climate, edited by: Siedler, G., Church, J., and Gould, J., Academic Press, San Diego, 303-314, 2001.

Griffies, S. M.: The Gent-McWilliams skew-flux, J. Phys. Oceanogr., 28, 831-841, 1998.

Harms, S., Fahrbach, E., and Strass, V. H.: Sea ice transports in the Weddell Sea, J. Geophys. Res., 106, 9057-9074, 2001.

Harvey, L. D. D.: Characterizing and comparing the control-run variability of eight coupled AOGCMs and of observations. Part 2: precipitation, Clim. Dynam., 21, 647-658, 2003.

Hasumi, H.: Sensitivity of the global thermohaline circulation to interbasin freshwater transport by the atmosphere and the Bering Strait throughflow, J. Climate, 15, 2516-2526, 2002.

Haug, G. H. and Tiedemann, R.: Effect of the formation of the Isthmus of Panama on Atlantic Ocean thermohaline circulation, Nature, 393, 673-676, 1998.

Holland, M. M., Bitz, C. M., Hunke, E. C., Lipscomb, W. H., and Schramm, J. L.: Influence of the sea ice thickness distribution on polar climate in CCSM3, J. Climate, 19, 2398-2414, 2006.

Huber, M. and Nof, D.: The ocean circulation in the Southern Hemisphere and its climatic impacts in the Eocene, Palaeogeogr., Palaeoclimat., Palaeoecol., 231, 9-28, 2006.

Huber, M. and Sloan, L. C.: Heat transport, deep waters, and thermal gradients: Coupled simulation of an Eocene greenhouse climate, Geophys. Res. Lett., 28, 3481-3484, 2001.

Hunke, E. C. and Dukowicz, J. K.: An elastic-viscous-plastic model for sea ice dynamics, J. Phys. Oceanogr., 27, 1849-1867, 1997.

Jongma, J. I., Prange, M., Renssen, H., and Schulz, M.: Amplification of Holocene multicentennial climate forcing by mode transitions in North Atlantic overturning circulation, Geophys. Res. Lett., 34, L15706, doi:10.1029/2007GL030642, 2007.

Kantha, L. H. and Clayson, C. A.: Numerical models of oceans and oceanic processes, Academic Press, 940 pp., 2000.

Kiehl, J. T. and Gent, P. R.: The Community Climate System Model, version 2, J. Climate, 17, 3666-3682, 2004.

Koesters, F., Kaese, R., Fleming, K., and Wolf, D.: Denmark Strait overflow for Last Glacial Maximum to Holocene conditions, Paleoceanogr., 19, PA2019, doi:10.1029/2003PA000972, 2004.

Lamb, P. J.: Case studies of tropical Atlantic surface circulation patterns during recent sub-saharan weather anomalies: 1967 and 1968, Mon. Weather Rev., 106, 482-491, 1978.

Lambert, S. J. and Boer, G. J.: CMIP1 evaluation and intercomparison of coupled climate models, Clim. Dynam., 17, 83-106, 2001.

Large, W. G. and Danabasoglu, G.: Attribution and impacts of upper-ocean biases in CCSM3, J. Climate, 19, 2325-2346, 2006.

Large, W. G., McWilliams, J. C., and Doney, S. C.: Oceanic vertical mixing: A review and a model with a nonlocal boundary layer parameterization, Rev. Geophys., 32, 363-403, 1994.

Latif, M., Sperber, K., Arblaster, J., et al.: ENSIP: the El Niño simulation intercomparison project, Clim. Dynam., 18, 255-276, 2001.

Laxon, S., Peacock, N., and Smith, D.: High interannual variability of sea ice thickness in the Arctic region, Nature, 425, 947-950, 2003.

Legates, D. R. and Willmott, C. J.: Mean seasonal and spatial variability in gauge-corrected, global precipitation, Int. J. Climatol., 10, 111-127, 1990. 
Li, J. L., Zhang, X. H., Yu, Y. Q., and Dai, F. S.: Primary reasoning behind the double ITCZ phenomenon in a coupled oceanatmosphere general circulation model, Adv. Atmos. Sci., 21, 857-867, 2004.

Marotzke, J.: Boundary mixing and the dynamics of threedimensional thermohaline circulations, J. Phys. Oceanogr., 27, 1713-1728, 1997.

McDermott, D. A.: The regulation of northern overturning by Southern Hemisphere winds, J. Phys. Oceanogr., 26, 1234-1255, 1996.

Mechoso, C. R., Robertson, A. W., Barth, N., et al.: The seasonal cycle over the tropical Pacific in coupled ocean-atmosphere general circulation models, Mon. Weather Rev., 123, 2825-2838, 1995.

Meehl, G. A., Arblaster, J. M., Lawrence, D. M., Seth, A., Schneider, E. K., Kirtman, B. P., and Min, D.: Monsoon regimes in the CCSM3, J. Climate, 19, 2482-2495, 2006.

Meehl, G. A., Gent, P. R., Arblaster, J. M., Otto-Bliesner, B. L., Brady, E. C., and Craig, A.: Factors that affect the amplitude of El Niño in global coupled climate models, Clim. Dynam., 17, 515-526, 2001.

Meehl, G. A., Stocker, T. F., Collins, W. D., et al.: Global climate projections, in: Climate Change 2007: The physical science basis (Contribution of Working Group I to the Fourth Assessment Report of the Intergovernmental Panel on Climate Change), edited by: Solomon, S., et al., Cambridge University Press, Cambridge, 747-845, 2007.

Mikolajewicz, U., Groeger, M., Maier-Reimer, E., Schurgers, G., Vizcaino, M., and Winguth, A. M. E.: Long-term effects of anthropogenic $\mathrm{CO} 2$ emissions simulated with a complex earth system model, Clim. Dynam., 28, 599-633, 2007.

Min, S.-K., Legutke, S., Hense, A., and Kwon, W.-T.: Climatology and internal variability in a 1000 -year control simulation with the coupled climate model ECHO-G, M\&D Technical Report, No. 2, Max Planck Institute for Meteorology, Hamburg, Germany, 67 pp., 2004.

Oppo, D. W., McManus, J. F., and Cullen, J. L.: Deepwater variability in the Holocene epoch, Nature, 422, 277-278, 2003.

Peltier, W. R. and Solheim, L. P.: The climate of the Earth at Last Glacial Maximum: statistical equilibrium state and a mode of internal variability, Quat. Sci. Rev., 23, 335-357, 2004

Peterson, R. G. and Stramma, L.: Upper-level circulation in the South Atlantic, Prog. Oceanogr., 26, 1-73, 1991.

Piotrowski, A. M., Goldstein, S. L., Hemming, S. R., and Fairbanks, R. G.: Temporal relationship of carbon cycling and ocean circulation at glacial boundaries, Science, 307, 1933-1938, 2005.

Prange, M.: Influence of Arctic freshwater sources on the circulation in the Arctic Mediterranean and the North Atlantic in a prognostic ocean/sea-ice model, Reports on Polar and Marine Research, No. 468, Alfred Wegener Institute, Bremerhaven, Germany, 220 pp., 2003

Prange, M. and Gerdes, R.: The role of surface freshwater flux boundary conditions in Arctic Ocean modelling, Ocean Model., 13, 25-43, 2006.

Prange, M., Lohmann, G., and Paul, A.: Influence of vertical mixing on the thermohaline hysteresis: Analyses of an OGCM, J. Phys. Oceanogr., 33, 1707-1721, 2003.

Prange, M., Lohmann, G., Romanova, V., and Butzin, M.: Modelling tempo-spatial signatures of Heinrich Events: Influence of the climatic background state, Quat. Sci. Rev., 23, 521-527, 2004.

Rahmstorf, S.: Ocean circulation and climate during the past 120,000 years, Nature, 419, 207-214, 2002.

Rothrock, D. A., Zhang, J., and Yu, Y.: The arctic ice thickness anomaly of the 1990s: A consistent view from observations and models, J. Geophys. Res., 108, 3083, doi:10.1029/2001JC001208, 2003.

Schmittner, A. and Weaver, A. J.: Dependence of multiple climate states on ocean mixing parameters, Geophys. Res. Lett., 28, 1027-1030, 2001.

Schulz, M., Prange, M., and Klocker, A.: Low-frequency oscillations of the Atlantic Ocean meridional overturning circulation in a coupled climate model, Clim. Past, 3, 97-107, 2007, http://www.clim-past.net/3/97/2007/.

Seo, H., Jochum, M., Murtugudde, R., and Miller, A. J.: Effect of ocean mesoscale variability on the mean state of tropical Atlantic climate, Geophys. Res. Lett., 33, L09606, doi:10.1029/2005GL025651, 2006.

Severinghaus, J. P. and Brook, E. J.: Abrupt climate change at the end of the last glacial period inferred from trapped air in polar ice, Science, 286, 930-934, 1999.

Smith, R. and Gent, P.: Reference manual for the Parallel Ocean Program (POP), Technical Report, Los Alamos National Laboratory, Los Alamos, New Mexico, National Center for Atmospheric Research, Boulder, Colorado, http://www.ccsm.ucar.edu/ models/ccsm2.0.1/pop, 2002.

Smith, R. D. and McWilliams, J. C.: Anisotropic horizontal viscosity for ocean models, Ocean Model., 5, 129-156, 2003.

Spencer, R. W.: Global oceanic precipitation from the MSU during 1979-91 and comparisons to other climatologies, J. Climate, 6, 1301-1326, 1993.

Stammer, D., Wunsch, C., Giering, R., et al.: Volume, heat, and freshwater transports of the global ocean circulation 1993-2000 estimated from a general circulation model constrained by World Ocean Circulation Experiment (WOCE) data, J. Geophys. Res., 108, 3007, doi:10.1029/2001JC001115, 2003.

Steele, M., Morley, R., and Ermold, W.: PHC: a global ocean hydrography with a high quality Arctic Ocean, J. Climate, 14, 2079-2087, 2001.

Stouffer, R. J., Dixon, K. W., Spelman, M. J., et al.: Investigating the causes of the response of the thermohaline circulation to past and future climate changes, J. Climate, 19, 1365-1387, 2006.

Strass, V. H. and Fahrbach, E.: Temporal and regional variation of sea ice draft and coverage in the Weddell Sea obtained from upward looking sonars, in: Antarctic sea ice - Physical processes, interactions, and variability, edited by: Jeffries, M. O., Antarctic Res. Ser., 74, American Geophys. Union, Washington D.C., 123-139, 1998.

Torrence, C. and Compo, G. P.: A practical guide to wavelet analysis, B. Am. Meteorol. Soc., 79, 61-78, 1998.

van Oldenborgh, G. J., Philip, S. Y., and Collins, M.: El Niño in a changing climate: a multi-model study, Ocean Sci., 1, 81-95, 2005 , http://www.ocean-sci.net/1/81/2005/.

Vertenstein, M., Oleson, K., and Levis, S.: CLM2.0 User's Guide, Technical Report, National Center for Atmospheric Research, Boulder, Colorado, http://www.ccsm.ucar.edu/models/ccsm2.0. 1/clm2, 2002. 
Voelker, A. H. L. and workshop participants: Global distribution of centennial-scale records for marine isotope stage (MIS) 3: a database, Quat. Sci. Rev., 21, 1185-1214, 2002.

Wadley, M. R. and Bigg, G. R.: Impact of flow through the Canadian Archipelago on the North Atlantic and Arctic thermohaline circulation: an ocean modelling study, Q. J. Roy. Meteor. Soc., 128, 2187-2203, 2002.

Wang, D.: A note on using the accelerated convergence method in climate models, Tellus A, 53, 27-34, 2001.

Webb, D. J. and de Cuevas, B. A.: On the fast response of the Southern Ocean to changes in the zonal wind, Ocean Sci., 3, 417-427, 2007 ,

http://www.ocean-sci.net/3/417/2007/.
Wittenberg, A. T., Rosati, A., Lau, N.-C., and Ploshay, J. J.: GFDL's CM2 global coupled climate models. Part III: Tropical Pacific climate and ENSO, J. Climate, 19, 698-722, 2006.

Wright, D. G. and Stocker, T. F.: Sensitivities of a zonally averaged global ocean circulation model, J. Geophys. Res., 97, 1270712730, 1992.

Yeager, S. G., Shields, C. A., Large, W. G., and Hack, J. J.: The low-resolution CCSM3, J. Climate, 19, 2545-2566, 2006.

Zhang, G. J. and Wang, H.: Toward mitigating the double ITCZ problem in NCAR CCSM3, Geophys. Res. Lett., 33, L06709, doi:10.1029/2005GL025229, 2006. 